Check for updates

Cite this: RSC Adv., 2018, 8, 36298

Received 4th August 2018

Accepted 18th October 2018

DOI: $10.1039 / c 8 r a 06561 f$

rsc.li/rsc-advances

\section{Bis-(salicylaldehyde-benzhydrylimino)nickel complexes with different electron groups: crystal structure and their catalytic properties toward (co) polymerization of norbornene and 1-hexene $\uparrow$}

\author{
Xiaohui He, (D) *a Guangshui Tu, ${ }^{a}$ Feng Zhang, ${ }^{\text {a }}$ Shengmei Huang, ${ }^{\text {ac }}$ \\ Changwen Cheng, ${ }^{a}$ Chuanyi Zhu, ${ }^{a}$ Yapeng Duan, ${ }^{a}$ Suli Wang ${ }^{a}$ and Defu Chen ${ }^{b}$
}

Eight bis-(salicylaldehyde-benzhydrylimino)nickel complexes with different electron groups (Ni1-Ni8), $\mathrm{Ni}$ $\left\{\left(3-\mathrm{R}_{1}\right)\left(5-\mathrm{R}_{2}\right) \mathrm{C}_{6} \mathrm{H}_{2}(\mathrm{O}) \mathrm{CHNCH}\left(\mathrm{C}_{6} \mathrm{H}_{5}\right)_{2}\right\}_{2},\left(\mathrm{R}_{1}=\mathrm{H}, \mathrm{R}_{2}=\mathrm{H}, \mathrm{Ni1} ; \mathrm{R}_{1}=\mathrm{H}, \mathrm{R}_{2}=\mathrm{CH}_{3}, \mathrm{Ni2} ; \mathrm{R}_{1}=\mathrm{H}, \mathrm{R}_{2}=\mathrm{OCH}_{3}\right.$, $\mathrm{Ni3} ; \mathrm{R}_{1}=\mathrm{H}, \mathrm{R}_{2}=\mathrm{Br}, \mathrm{Ni4} ; \mathrm{R}_{1}=\mathrm{CH}_{3}, \mathrm{R}_{2}=\mathrm{H}, \mathrm{Ni5} ; \mathrm{R}_{1}=\mathrm{OCH}_{3}, \mathrm{R}_{2}=\mathrm{H}, \mathrm{Ni6} ; \mathrm{R}_{1}=\mathrm{Br}, \mathrm{R}_{2}=\mathrm{Br}, \mathrm{Ni7} ; \mathrm{R}_{1}=\mathrm{Cl}$, $\mathrm{R}_{2}=\mathrm{Cl}$, Ni8), were synthesized and their crystal structures were characterized using single crystal $X$-ray diffraction. The results revealed that Ni1-Ni6 belong to the monoclinic system (space group P2(1)/n), Ni7 belongs to the monoclinic system (space group $\mathrm{C} 2 / \mathrm{c}$ ) and $\mathrm{Ni8}$ belongs to the triclinic system (space group $P \overline{1})$. All nickel complexes exhibited high activities $\left(0.46-2.07 \times 10^{6} \mathrm{~g}_{\text {polymer }} \mathrm{mol}_{\mathrm{Ni}}{ }^{-1} \mathrm{~h}^{-1}\right.$ ) toward norbornene homopolymerization, and a strong electron-withdrawing group on the salicylaldimino aromatic ring can enhance the catalytic activity and favor polymerization. Ni1 and Ni2 exhibited high activities $\left(0.55-2.40 \times 10^{5} \mathrm{~g}_{\text {polymer }}\right.$ mol $\left._{\mathrm{Ni}^{-1}} \mathrm{~h}^{-1}\right)$ toward copolymerization of norbornene and 1-hexene in the presence of $\mathrm{B}_{(}\left(\mathrm{C}_{6} \mathrm{~F}_{5}\right)_{3}$. The 1-hexene content in the copolymers could be controlled up to 7.98$12.50 \%$ by varying the comonomer feed ratio of 1 -hexene from 10 to $50 \%$. It is observed that when the 5 -position of the salicylaldimino aromatic ring has a substituent $\left(-\mathrm{CH}_{3}\right)$, the 1-hexene insertion rate is lower than that without a substituent. In addition, the polymers showed high molecular weights (1.5-2.4 $\times 10^{5} \mathrm{~g} \mathrm{~mol}^{-1}$ ) and narrow molecular weight distributions (1.62-1.89). The obtained polymers were also verified to be amorphous copolymers and had high thermal stability, good solubility and optical transparency.

\section{Introduction}

Over the last few decades, polyolefin materials as a good substitute for engineering plastics and optical device apparatus attracted much attention in the scientific community and industry. ${ }^{1-3}$ Norbornene and its derivatives can be very easy to polymerize because of the presence of their bicyclic structures. There are three polymerization methods: ringopening metathesis polymerization (ROMP), ${ }^{4-8}$ cationic or radical polymerization, ${ }^{9}$ and vinyl-addition polymerization. ${ }^{\mathbf{1 0 - 1 7}}$ The polymers obtained by the vinyl addition

\footnotetext{
${ }^{a}$ School of Materials Science and Engineering, Nanchang University, 999 Xuefu Avenue, Nanchang 330031, China.E-mail: hexiaohui@ncu.edu.cn

${ }^{b}$ School of Civil Engineering and Architecture, Nanchang University, 999 Xuefu Avenue, Nanchang 330031, China

${ }^{c}$ School of Materials Science and Engineering, Nanchang Hangkong University, Nanchang 330063, China

† Electronic supplementary information (ESI) available. CCDC 1575905, 1575909, 1587113, 1817084, 1830324, 1843964, 1843971 and 1851039. For ESI and crystallographic data in CIF or other electronic format see DOI: 10.1039/c8ra06561f
}

polymerization method had high thermal stability, high optical permeability, a low dielectric constant, low moisture absorption and other excellent properties and were widely used in micro electronics and optics. However, the further development of norbornene is hampered by its poor bond properties, low solubility and poor mechanical properties. At present, the introduction of polar groups ${ }^{18-20}$ or flexible chains $^{\mathbf{2 1 - 2 5}}$ on the norbornene backbone is the most effective means to solve this problem. In order to achieve this goal, it is important to synthesize some efficient catalysts. It is wellknown that conventional Ziegler-Natta catalysts ${ }^{26,27}$ and metallocene catalysts ${ }^{\mathbf{2 8 - 3 0}}$ have many disadvantages due to their polar centers as early transition metals, for instance, poor tolerance to polar groups and large amounts of cocatalyst. However, owing to the lower oxophilicity, single active site and resistance toward deactivation by polar functionalities, the design of late-transition-metal catalysts has attracted widespread interest. ${ }^{31-35}$ The usual late-transition-metal catalysts are $\mathrm{Ni}$ (II) and $\mathrm{Pd}(\mathrm{II})$ complexes. Comprehensive investigations had approved Ni(II) complexes because of their 
superior catalytic performance, polymer properties and their expounded reaction mechanisms.

Norbornene is a typical cycloolefin with many advantages of cycloolefins, but due to the presence of bicyclic skeletons in the polymer, it is brittle and has a small elongation at break. In order to improve its defects, the copolymer obtained by copolymerizing norbornene with $\alpha$-olefin ${ }^{22,23,36}$ not only can reserve the heat resistance and dimensional stability of polynorbornene, but also has excellent optical properties, good processing and solubility, which has attracted scholars's attention at both home and abroad. For example, Kaminsky group $^{37}$ achieved the copolymerization of norbornene with ethylene using a metallocene catalyst. The results showed that the glass transition temperature decreases with the increase of ethylene content in the copolymer, and the flexibility and processing performance of the polymer can be improved. Shiono group $^{38}$ achieved the copolymerization of norbornene with longchain alpha-olefins (1-hexene, 1-octene and 1-decene) through a titanium metal catalyst. And the catalyst afforded low molecular weight distribution, high light transmittance (up to 90\%) and excellent processing performance.

In this study, a series of salicylaldimine ligands, $\left(3-\mathrm{R}_{1}\right)(5-$ $\left.\mathrm{R}_{2}\right) \mathrm{C}_{6} \mathrm{H}_{2}(\mathrm{OH}) \mathrm{CHNCH}\left(\mathrm{C}_{6} \mathrm{H}_{5}\right)_{2}\left(\mathrm{R}_{1}=\mathrm{H}, \mathrm{R}_{2}=\mathrm{H}, \mathrm{L} 1 ; \mathrm{R}_{1}=\mathrm{H}, \mathrm{R}_{2}\right.$ $=\mathrm{CH}_{3}, \mathrm{~L} 2 ; \mathrm{R}_{1}=\mathrm{H}, \mathrm{R}_{2}=\mathrm{OCH}_{3}, \mathrm{~L} 3 ; \mathrm{R}_{1}=\mathrm{H}, \mathrm{R}_{2}=\mathrm{Br}, \mathrm{L} 4 ; \mathrm{R}_{1}=$ $\mathrm{CH}_{3}, \mathrm{R}_{2}=\mathrm{H}, \mathrm{L} 5 ; \mathrm{R}_{1}=\mathrm{OCH}_{3}, \mathrm{R}_{2}=\mathrm{H}, \mathrm{L} 6 ; \mathrm{R}_{1}=\mathrm{Br}, \mathrm{R}_{2}=\mathrm{Br}, \mathrm{L}$; $\mathrm{R}_{1}=\mathrm{Cl}, \mathrm{R}_{2}=\mathrm{Cl}$, L8) (L1-L8) and the corresponding bis(salicylaldehyde-benzhydrylimino)nickel complexes (Ni1$\mathrm{Ni8)}$ were synthesized, and the catalytic activities of complexes Ni1-Ni8 with only $\mathrm{B}\left(\mathrm{C}_{6} \mathrm{~F}_{5}\right)_{3}$ (ref. 39-42) as cocatalyst in norbornene homopolymerization were investigated. In addition, the Ni1 and Ni2 complexes for norbornene and 1hexene copolymerization were also investigated. Finally, the properties of polynorbornene were improved by introducing flexible chain, and the structure, thermal stability and optical properties of the copolymers were also characterized.

\section{Experimental}

All the operations involving air- and moisture-sensitive chemical compounds were performed under an atmosphere of purified and dried nitrogen using standard vacuum-line, schlenk or glovebox techniques.

\subsection{Materials}

The required tetrahydrofuran (THF) and toluene were dried over sodium/benzophenone for $48 \mathrm{~h}$ and distilled under dry nitrogen atmosphere. Norbornene (NB) was purchased from Alfa Aesar and purified by drying over metallic sodium and distilling under dry nitrogen atmosphere, then used as a solution $(0.4 \mathrm{~g}$ $\mathrm{mL}$ ) in toluene. 1-Hexene was purchased from Aladdin and the inhibitor was removed by washing three times with aqueous sodium hydroxide solution ( $5.0 \mathrm{wt} \%$ ), and then distillation over $\mathrm{CaH}_{2}$ under dry nitrogen atmosphere at a reduced pressure. Other chemical reagents available on the market are purchased and used without purification.

\subsection{Characterization}

The single crystal intensity data for the catalysts were collected with a Bruker Smart APEX II CCD system. The ${ }^{1} \mathrm{H}$ NMR and ${ }^{13} \mathrm{C}$ NMR spectra of the nickel complexes and copolymers were gained by a Bruker ARX 600 NMR spectrometer at ambient temperature with $\mathrm{CDCl}_{3}$ as solvent and tetramethylsilane (TMS) as an internal reference. The Fourier transform infrared (FT-IR) spectra were recorded by a Shimadzu IR Prestige-21 FTIR spectrophotometer. The molecular weight and molecular weight distribution of the polymers samples were gained by gel permeation chromatography (GPC, PL-GPC220), with a refractive index detector, chloroform as a solvent with a flow rate of $0.5 \mathrm{~mL} \mathrm{~min}^{-1}$ and detector at $40{ }^{\circ} \mathrm{C}$. Thermal gravimetric analysis (TGA) was carried out with a TAQ600 SDT for thermogravimetry from room temperature to $650{ }^{\circ} \mathrm{C}$ at a rate of $20{ }^{\circ} \mathrm{C} \mathrm{min}-1$ under nitrogen atmosphere. The wide-angle X-ray diffraction (XRD) curves of the polymers were gained with a Bruker D8 Focus Xray diffractometer, with monochromatic radiation at a wavelength of $1.54 \AA$ at a scanning rate of $2^{\circ} \mathrm{min}^{-1}$. Scanning was carried out with $2 \theta$ ranging from $3^{\circ}$ to $50^{\circ}$.

\subsection{Crystal structure determination}

The X-ray diffraction data of single crystals of the complexes were obtained with the $\omega-2 \theta$ scan mode of a Bruker Smart APEX II CCD diffractometer with graphite-monochromated Mo $\mathrm{K} \alpha$ radiation $(\lambda=0.71073 \mathrm{~nm})$. The structures were worked out using direct methods, and further refinements with full-matrix least-squares on $F^{2}$ were gained using the SHELXTL program package. All non-hydrogen atoms were refined anisotropically.

\subsection{Syntheses of pro-ligands (L1-L8) and nickel complexes (Ni1-Ni8)}

The syntheses and structures of the pro-ligands and nickel complexes were outlined in Scheme 1.

The typical synthetic means of the $\mathrm{C}_{6} \mathrm{H}_{4}(\mathrm{OH}) \mathrm{CHNCH}\left(\mathrm{C}_{6} \mathrm{H}_{5}\right)_{2}$ (L1) was described as follows: under a nitrogen atmosphere, salicylaldehyde $1.22 \mathrm{~g}(0.01 \mathrm{~mol})$, aminodiphenylmethane $1.83 \mathrm{~g}(0.01 \mathrm{~mol})$ and a catalytic amount of $p$-toluenesulfonic acid $(p-\mathrm{TsOH})$ were successively added to a $250 \mathrm{~mL}$ reaction flask equipped with a magnetic stirrer, then added to $150 \mathrm{~mL}$ toluene. The mixture was refluxed for $24 \mathrm{~h}$. The resulting water during the reaction was removed by using a Dean-Stark apparatus in the form of a water-toluene azeotrope. The crude product were further purified by silica column chromatography with $n$-hexane and ethyl acetate (20/1 in v/v) and were crystallized from a mixture of the $n$-hexane and ethyl acetate to get L1 as yellow crystals. Yield: $1.96 \mathrm{~g}(68.3 \%) .{ }^{1} \mathrm{H}$ NMR $\left(\mathrm{CDCl}_{3}, \delta\right.$, ppm): 13.51 (s, 1H, OH); $8.47(\mathrm{~s}, 1 \mathrm{H},-\mathrm{C}=\mathrm{N}-\mathrm{H}) ; 7.24-7.58(\mathrm{~m}$, $\left.10 \mathrm{H}, 2 \mathrm{C}_{6} \mathrm{H}_{5}\right) ; 6.86-7.24\left(\mathrm{~m}, 3 \mathrm{H}, \mathrm{C}_{6} \mathrm{H}_{4}\right) ; 5.62\left(\mathrm{~s}, 1 \mathrm{H}, \mathrm{C}_{13} \mathrm{H}_{11}\right)$. FTIR (KBr): 3343.22(w), 2928.01(w), 2762.30(w), 1725.69(w), 1661.36 (vs., $\left.\quad \nu_{\mathrm{C}=\mathrm{N}}\right), \quad 1592.06(\mathrm{~s}), \quad 1516.49(\mathrm{w}), \quad 1433.45(\mathrm{w})$, $1300.56(\mathrm{w})$. 


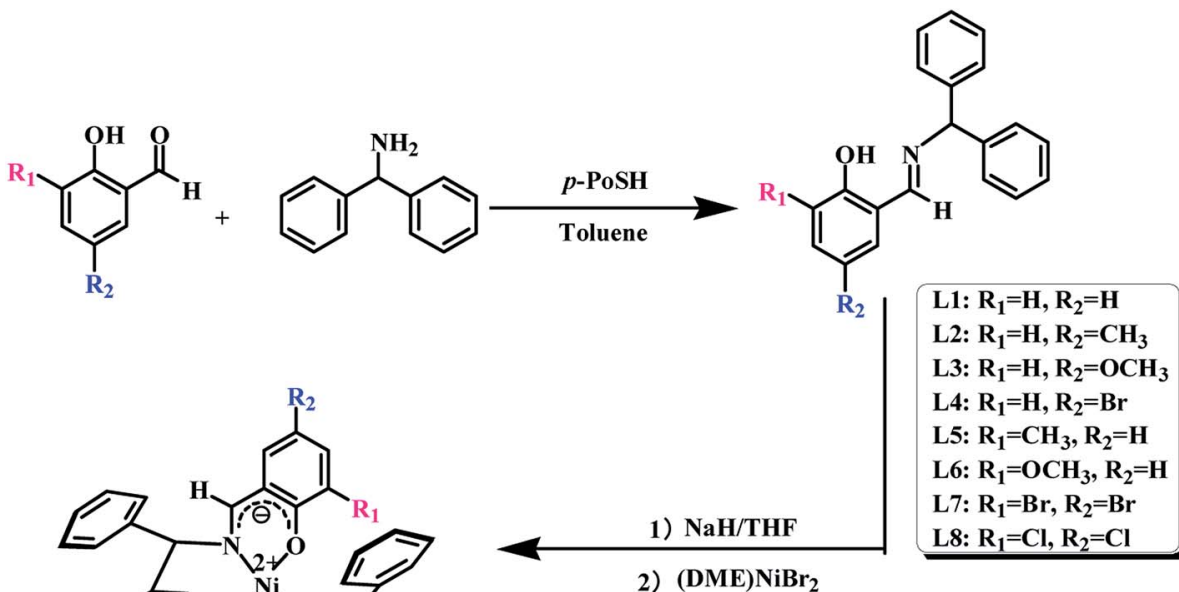

2) (DME) $\mathrm{NiBr}_{2}$

Ni1: $\mathrm{R}_{1}=\mathrm{H}, \mathrm{R}_{2}=\mathrm{H}$
Ni2: $\mathrm{R}_{1}=\mathrm{H}, \mathrm{R}_{2}=\mathrm{CH}_{3}$
Ni3: $\mathrm{R}_{1}=\mathrm{H}, \mathrm{R}_{2}=\mathrm{OCH}_{3}$
Ni4: $\mathrm{R}_{1}=\mathrm{H}, \mathrm{R}_{2}=\mathrm{Br}$
Ni5: $\mathrm{R}_{1}=\mathrm{CH}_{3}, \mathrm{R}_{2}=\mathrm{H}$
Ni6: $\mathrm{R}_{1}=\mathrm{OCH}_{3}, \mathrm{R}_{2}=\mathrm{H}$
Ni7: $\mathrm{R}_{1}=\mathrm{Br}, \mathrm{R}_{2}=\mathrm{Br}$
Ni8: $\mathrm{R}_{1}=\mathrm{Cl}, \mathrm{R}_{2}=\mathrm{Cl}$

Scheme 1 The synthetic routes of salicylaldehyde-benzhydrylimine ligands and bis-(salicylaldehyde-benzhydrylimino)nickel complexes

The other salicylaldimine ligands (L2-L8) were synthesized and characterized according to the method for L1 synthesizing, and yellow crystals were also obtained.

The typical synthetic procedure for $\mathrm{Ni}\left\{(3-\mathrm{H})(5-\mathrm{H}) \mathrm{C}_{6} \mathrm{H}_{2}(\mathrm{O})\right.$ $\left.\mathrm{CHNCH}\left(\mathrm{C}_{6} \mathrm{H}_{5}\right)_{2}\right\}_{2}$ (Ni1) was described as follow: ligand L1 $(0.574 \mathrm{~g}, 0.002 \mathrm{~mol})$ was added to a $100 \mathrm{~mL}$ Schlenk flask equipped with a magnetic stirrer, $0.06 \mathrm{~mol}$ of $60 \%$ sodium hydride was added to the reaction flask, and finally $20 \mathrm{~mL}$ of freshly distilled tetrahydrofuran solution was added. The mixed solution was stirred at room temperature for 8 hours for deprotonation. When the solution changed from yellow to orange, the solvent was removed in vacuo. Then, (DME) $\mathrm{NiBr}_{2}(1.0$ $\mathrm{mmol})$ and freshly distilled dichloromethane $(20 \mathrm{~mL})$ were added and stirred for 12 hours at room temperature. The dark-green crystal Ni1 complex was crystallized from dichloromethane in $70 \%$ yield. ${ }^{1} \mathrm{H}$ NMR $\left(\mathrm{CDCl}_{3}, \delta, \mathrm{ppm}\right): 8.45(\mathrm{~s}, 2 \mathrm{H}, 2 \mathrm{C}-\mathrm{N}-\mathrm{H}) ; 0.97-$ $1.49\left(\mathrm{~m}, 20 \mathrm{H}, 4 \mathrm{C}_{6} \mathrm{H}_{5}\right) ; 7.28-7.69\left(\mathrm{~m}, 8 \mathrm{H}, 2 \mathrm{C}_{6} \mathrm{H}_{4}\right) ; 5.62(\mathrm{~s}, 2 \mathrm{H}$, $\left.2 \mathrm{C}_{13} \mathrm{H}_{11}\right) .{ }^{13} \mathrm{C}$ NMR $\left(\mathrm{CDCl}_{3}, \delta, \mathrm{ppm}\right): 164.90,132.61,131.19$, $129.48,129.04,127.43,126.90,118.85,29.59$. Analysis calculated for Ni1: C, 75.94; H, 5.75; N, 4.32; found: C, 76.01; H, 5.78; N, 4.33.

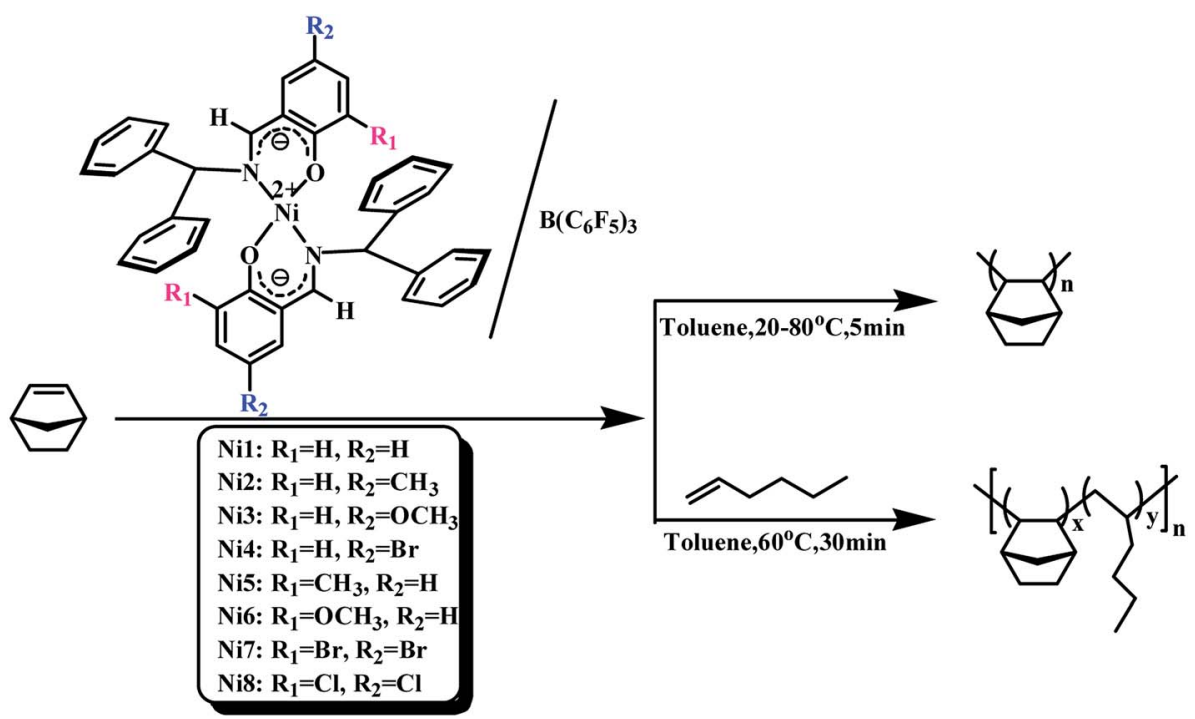

Scheme 2 Norbornene homopolymerization catalysed by Ni1-Ni8/B $\left(\mathrm{C}_{6} \mathrm{~F}_{5}\right)_{3}$ and copolymerization of norbornene and 1-hexene catalyzed by $\mathrm{Ni1}$ and $\mathrm{Ni2} / \mathrm{B}\left(\mathrm{C}_{6} \mathrm{~F}_{5}\right)_{3}$. 


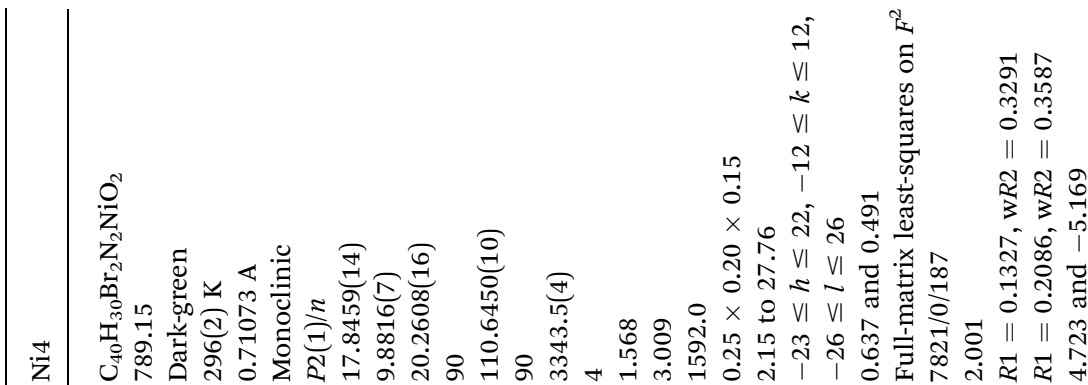

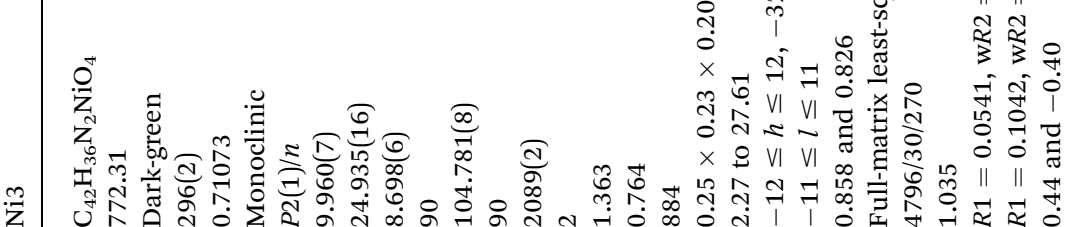

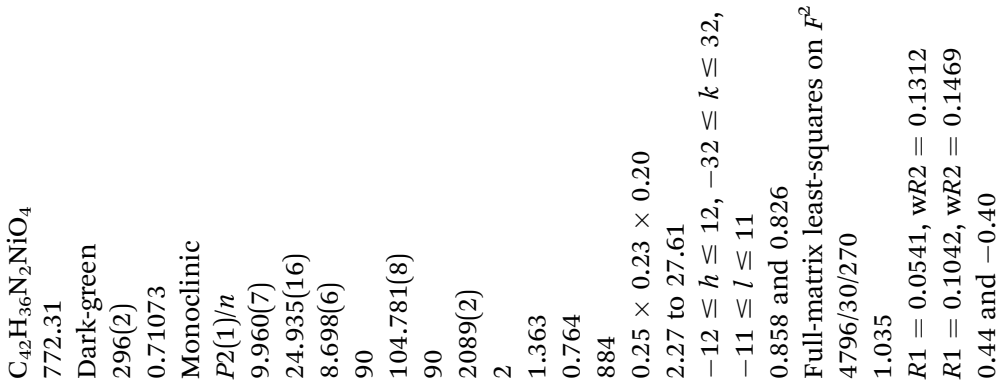

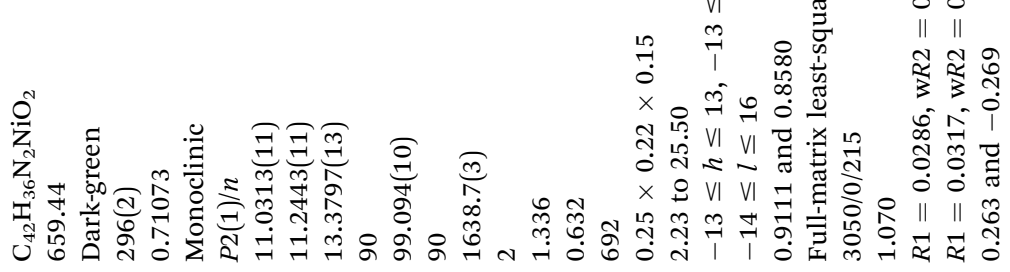
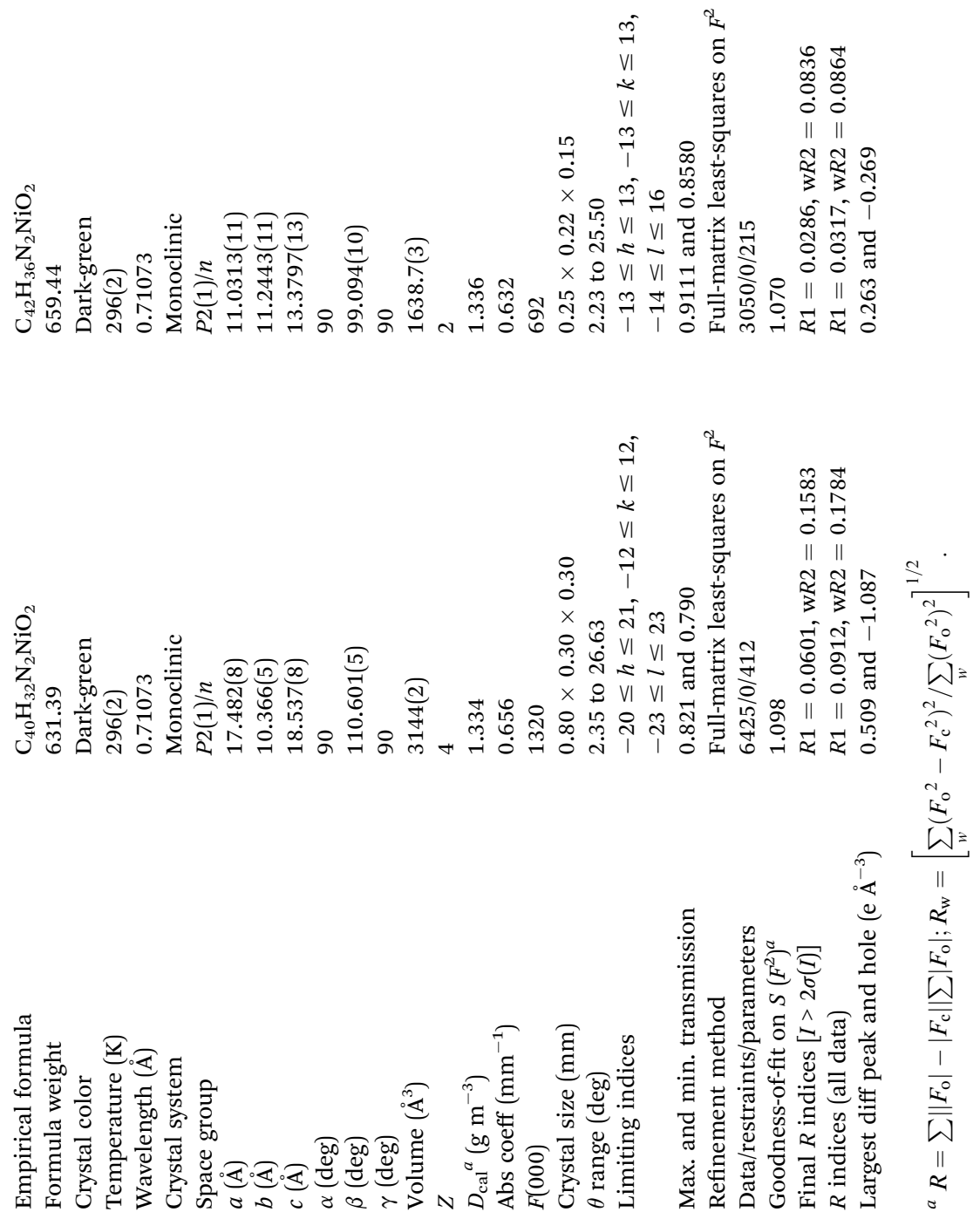


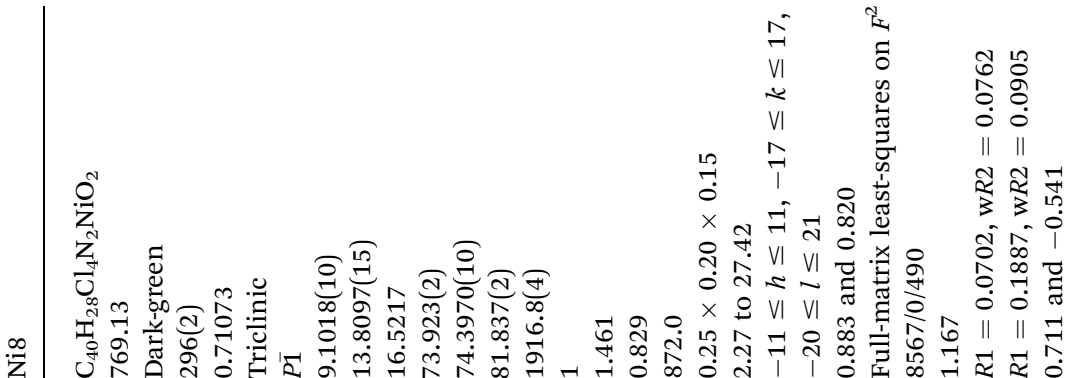

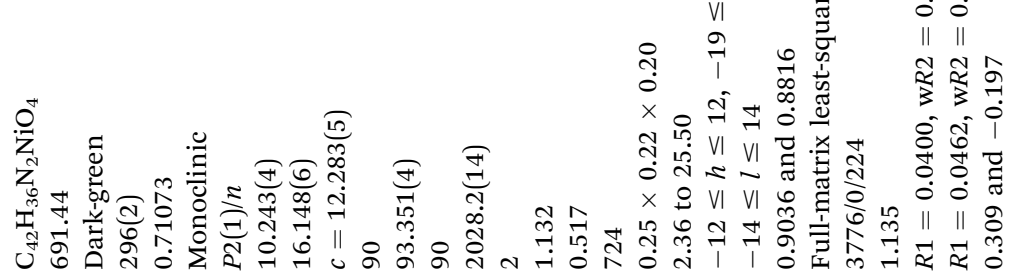
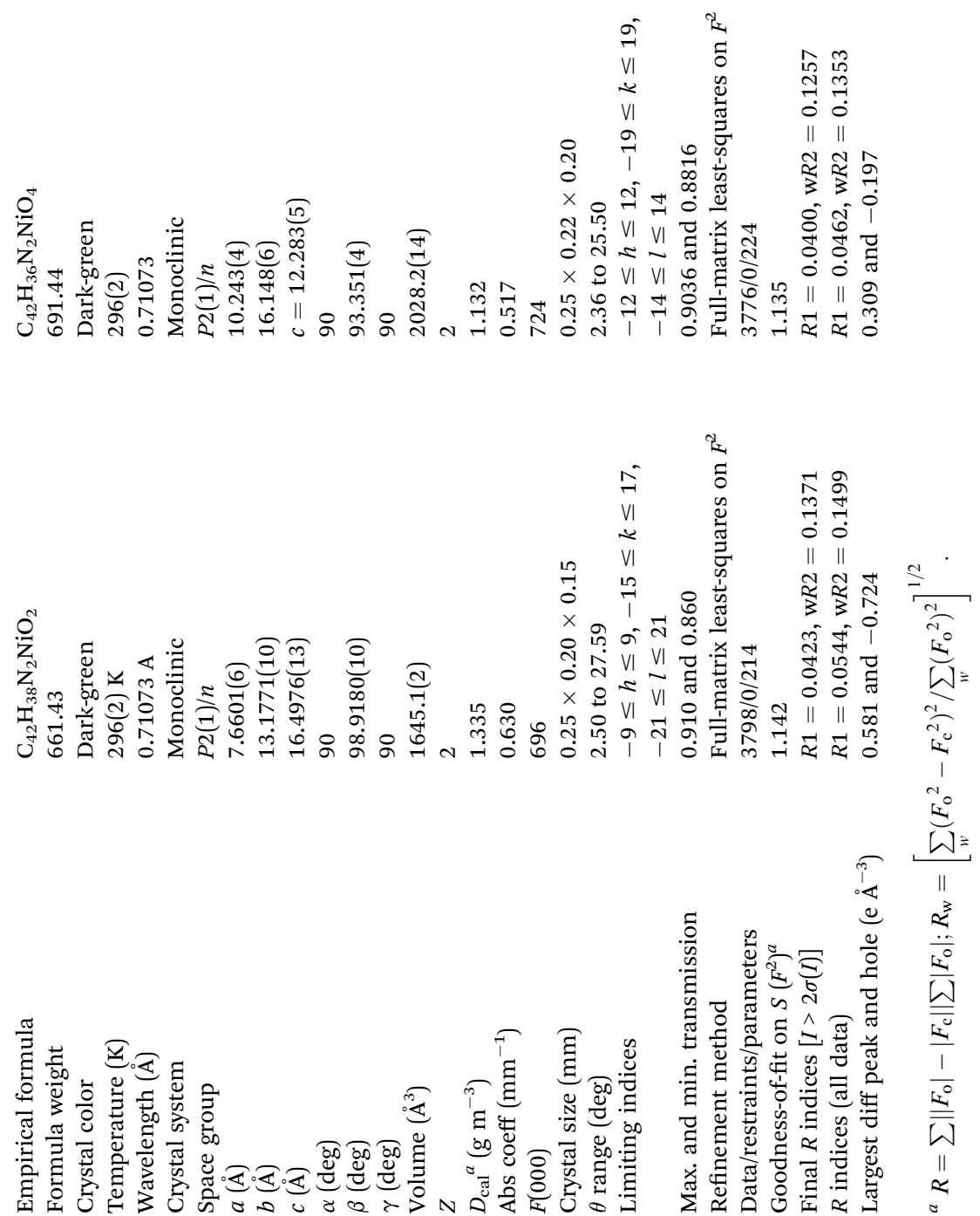


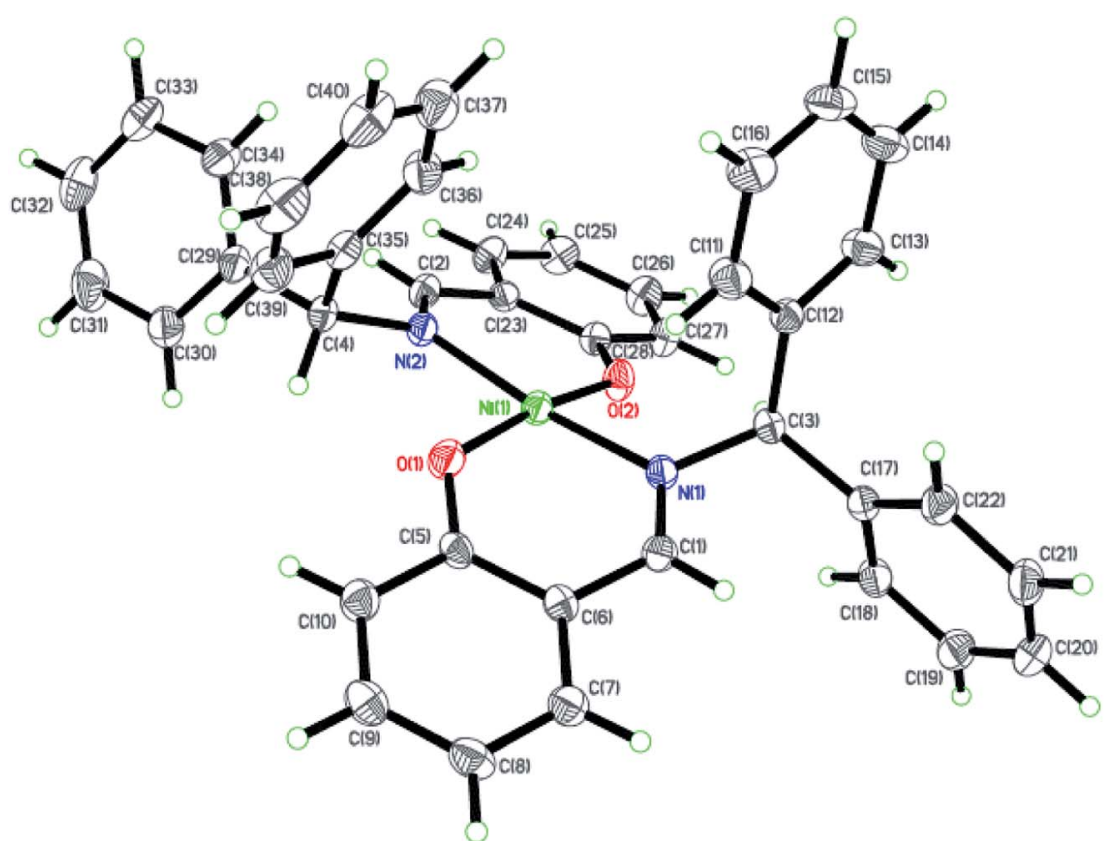

Fig. 1 ORTEP plots of Ni1 with thermal ellipsoids at the $30 \%$ probability level showing the atom-labeling scheme. Hydrogen atoms and solvent have been omitted for clarity.

The other Ni $\left\{\left(3-\mathrm{R}_{1}\right)\left(5-\mathrm{R}_{2}\right) \mathrm{C}_{6} \mathrm{H}_{2}(\mathrm{O}) \mathrm{CHNCH}\left(\mathrm{C}_{6} \mathrm{H}_{5}\right)_{2}\right\}_{2}$ (Ni2-Ni8) were synthesized and characterized according to the method for synthesizing Ni1, and dark-green crystals were also obtained.

\subsection{Polymerization of norbornene}

All manipulations were carried out under a dry nitrogen atmosphere. The polymerization process was as follows: the appropriate $\mathrm{B}\left(\mathrm{C}_{6} \mathrm{~F}_{5}\right)_{3}$ standard solution and a certain amount of toluene were added to the two-necked round bottom flask, then the appropriate amount toluene solution of norbornene (NB) $\left(0.4 \mathrm{~g} \mathrm{~mL}^{-1}\right)$ and the catalyst standard solution $(5 \times$ $10^{-3} \mathrm{~mol} \mathrm{~L}^{-1}$ ) were injected into the stirred solution in order. The reaction mixture was continuously stirred at the set temperature. The reaction was terminated by the addition of

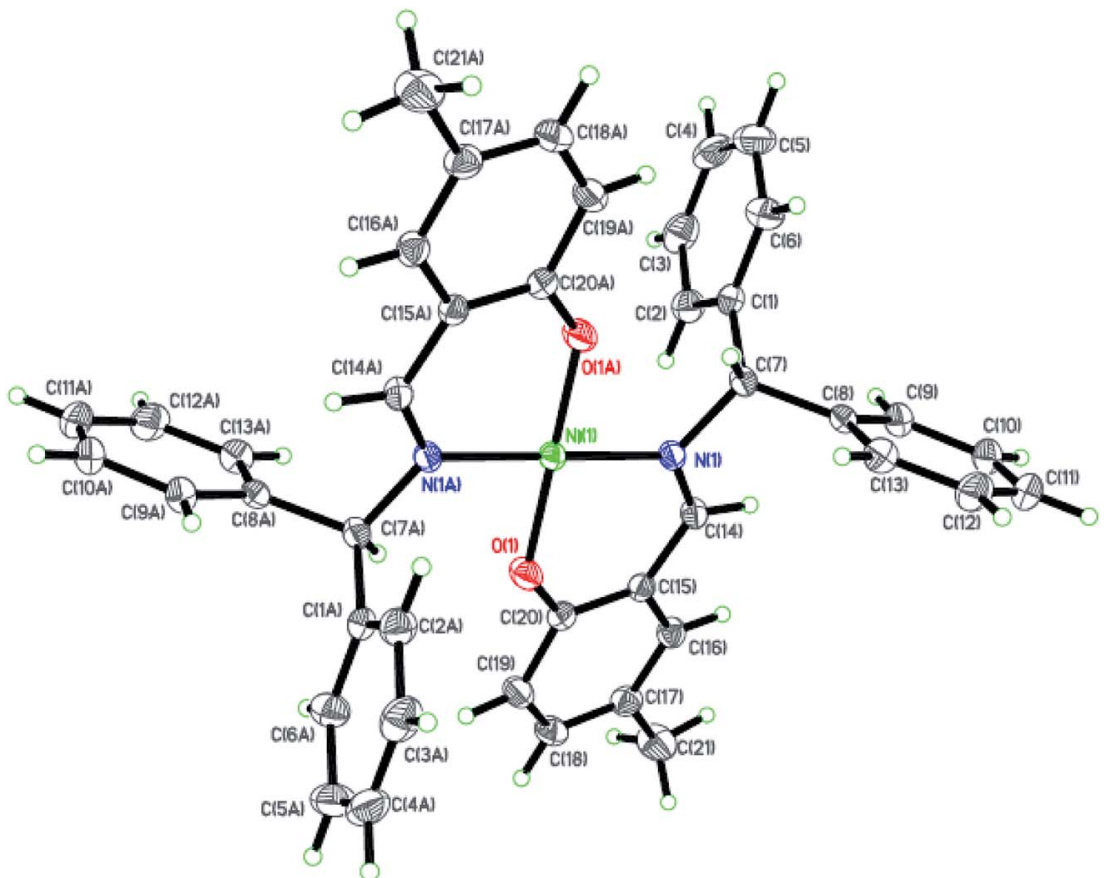

Fig. 2 ORTEP plots of $\mathrm{Ni} 2$ with thermal ellipsoids at the $30 \%$ probability level showing the atom-labeling scheme. Hydrogen atoms and solvent have been omitted for clarity. 


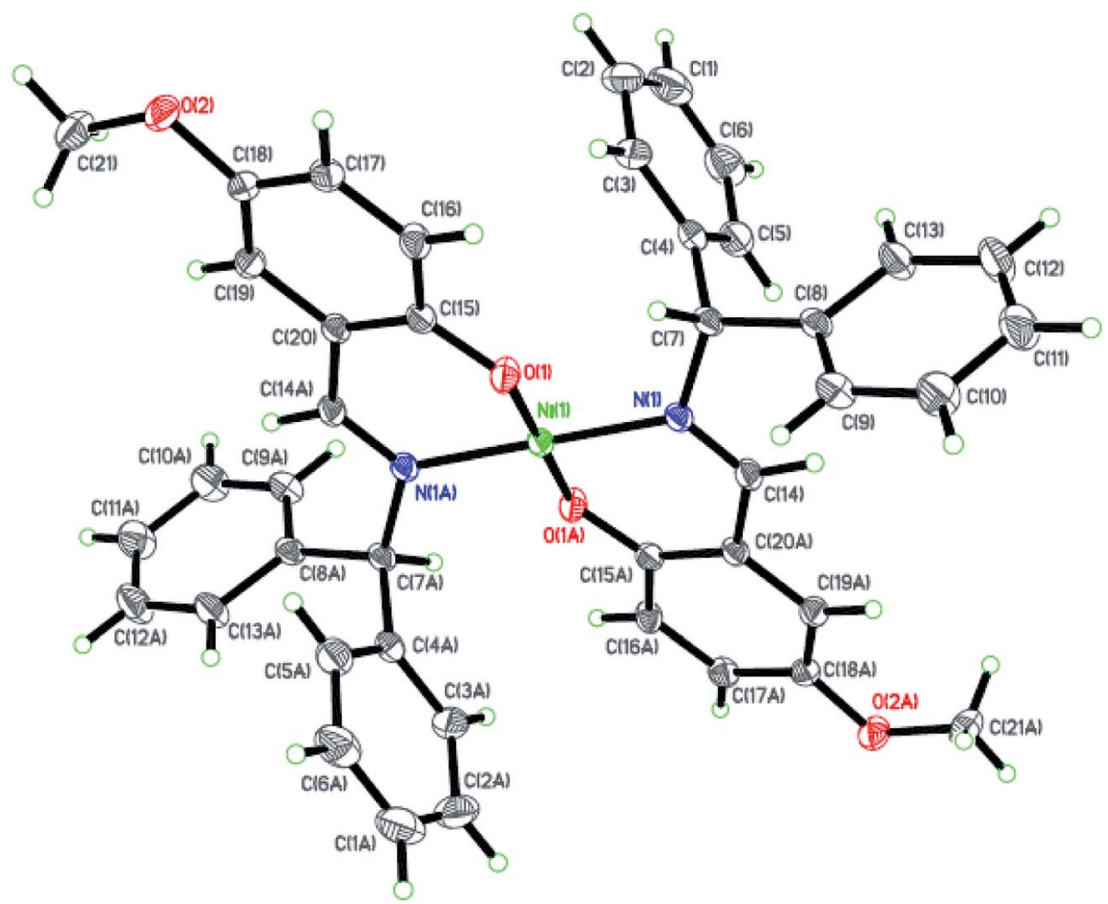

Fig. 3 ORTEP plots of Ni3 with thermal ellipsoids at the $30 \%$ probability level showing the atom-labeling scheme. Hydrogen atoms and solvent have been omitted for clarity.

a mixed solution of hydrochloric acid/methanol $(\mathrm{v} / \mathrm{v}=1 / 9)$. Finally, the resulting polymers were collected by filtration at room temperature and were dried in a vacuum at $50{ }^{\circ} \mathrm{C}$ until constant weight. The procedure was shown in Scheme 2 .

\subsection{Copolymerization of norbornene and 1-hexene}

The copolymerization process was as follows: norbornene standard solution $\left(0.4 \mathrm{~g} \mathrm{~mol}^{-1}\right)$, 1-hexene and toluene were added to a $100 \mathrm{~mL}$ two-necked round bottom flask under nitrogen atmosphere, and then a standard solution of $\mathrm{B}\left(\mathrm{C}_{6} \mathrm{~F}_{5}\right)_{3}$ $\left(5 \times 10^{-2} \mathrm{~mol} \mathrm{~L}^{-1}\right)$ and complexes $\left(5 \times 10^{-3} \mathrm{~mol} \mathrm{~L}^{-1}\right)$ were syringed into the well-stirred solution. The reaction mixture was continuously stirred for $1 \mathrm{~h}$ at $60{ }^{\circ} \mathrm{C}$. The reaction was terminated by the addition of a mixed solution of hydrochloric acid/ methanol $(\mathrm{v} / \mathrm{v}=1 / 9)$. The resulting polymers were collected by filtration at room temperature and were purified by

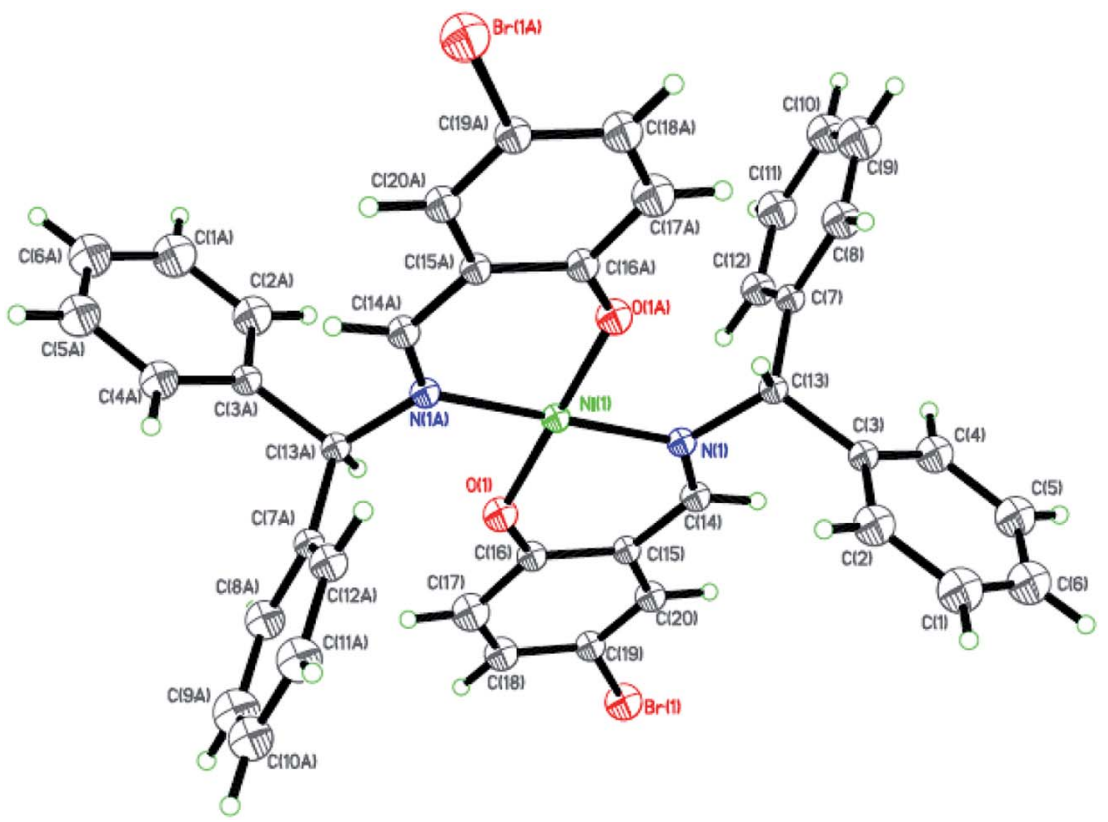

Fig. 4 ORTEP plots of $\mathrm{Ni} 4$ with thermal ellipsoids at the $30 \%$ probability level showing the atom-labeling scheme. Hydrogen atoms and solvent have been omitted for clarity. 


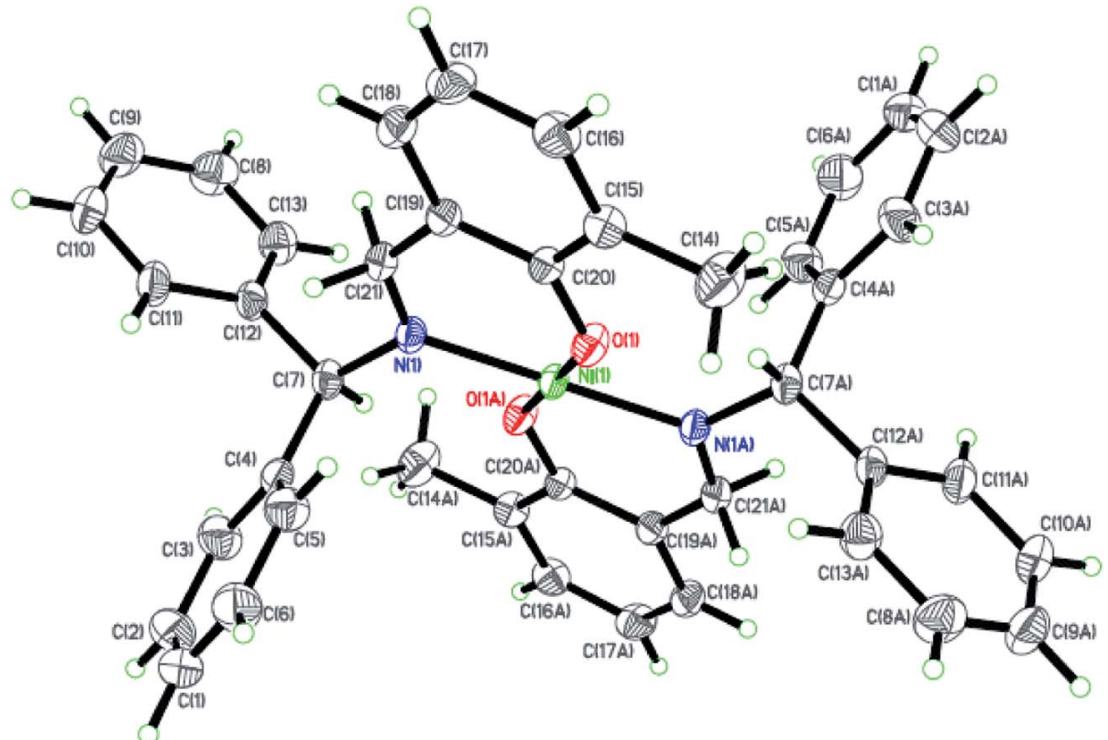

Fig. 5 ORTEP plots of Ni5 with thermal ellipsoids at the 30\% probability level showing the atom-labeling scheme. Hydrogen atoms and solvent have been omitted for clarity.

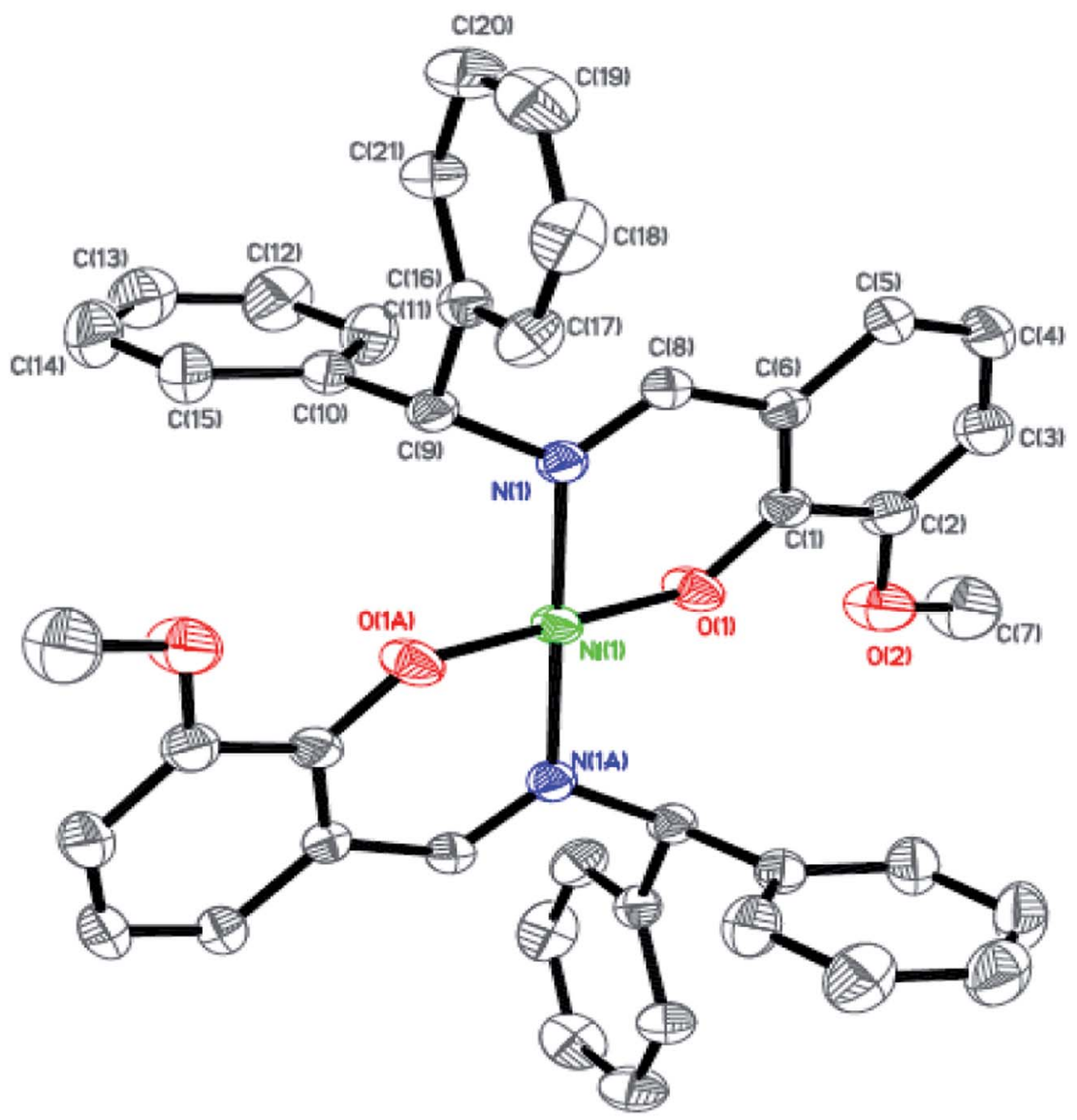

Fig. 6 ORTEP plots of Ni6 with thermal ellipsoids at the 30\% probability level showing the atom-labeling scheme. Hydrogen atoms and solvent have been omitted for clarity. 


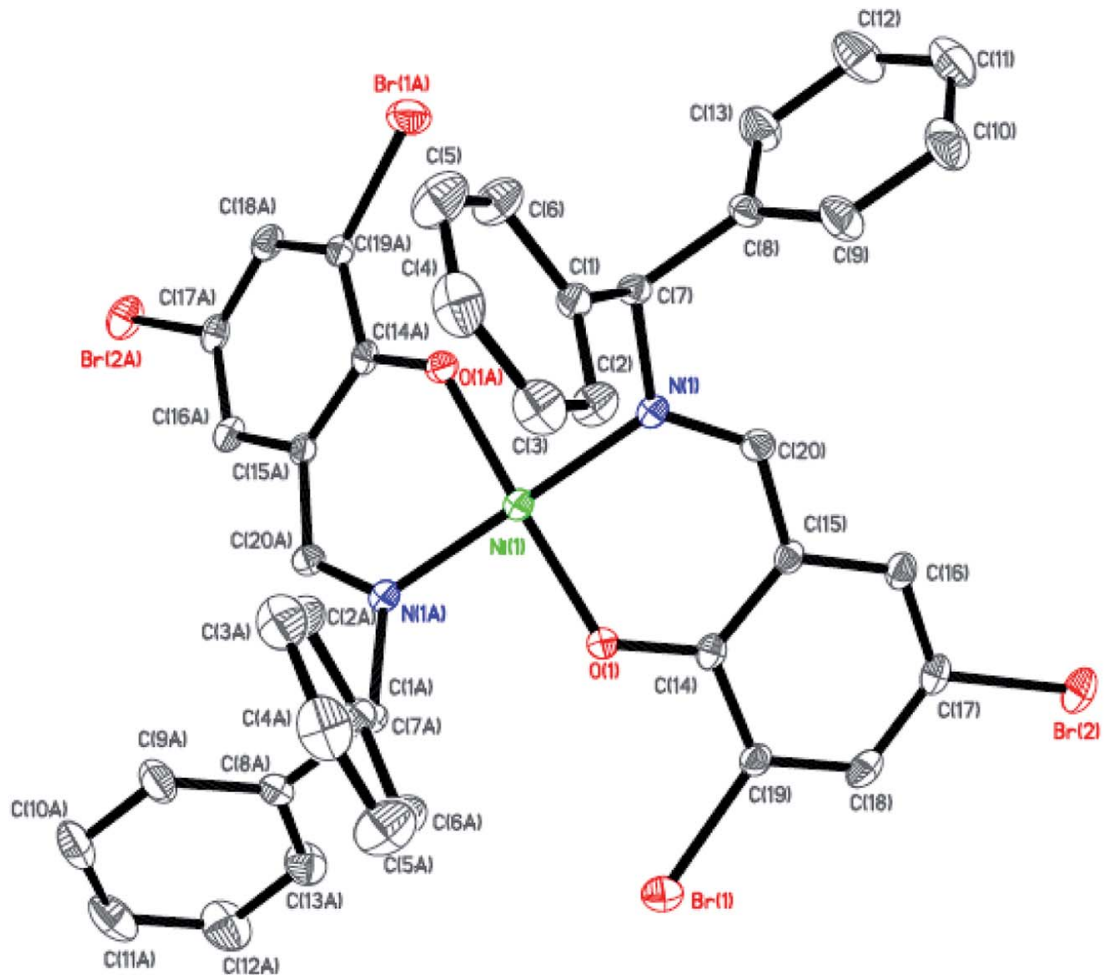

Fig. 7 ORTEP plots of $\mathrm{Ni} 7$ with thermal ellipsoids at the $30 \%$ probability level showing the atom-labeling scheme. Hydrogen atoms and solvent have been omitted for clarity.

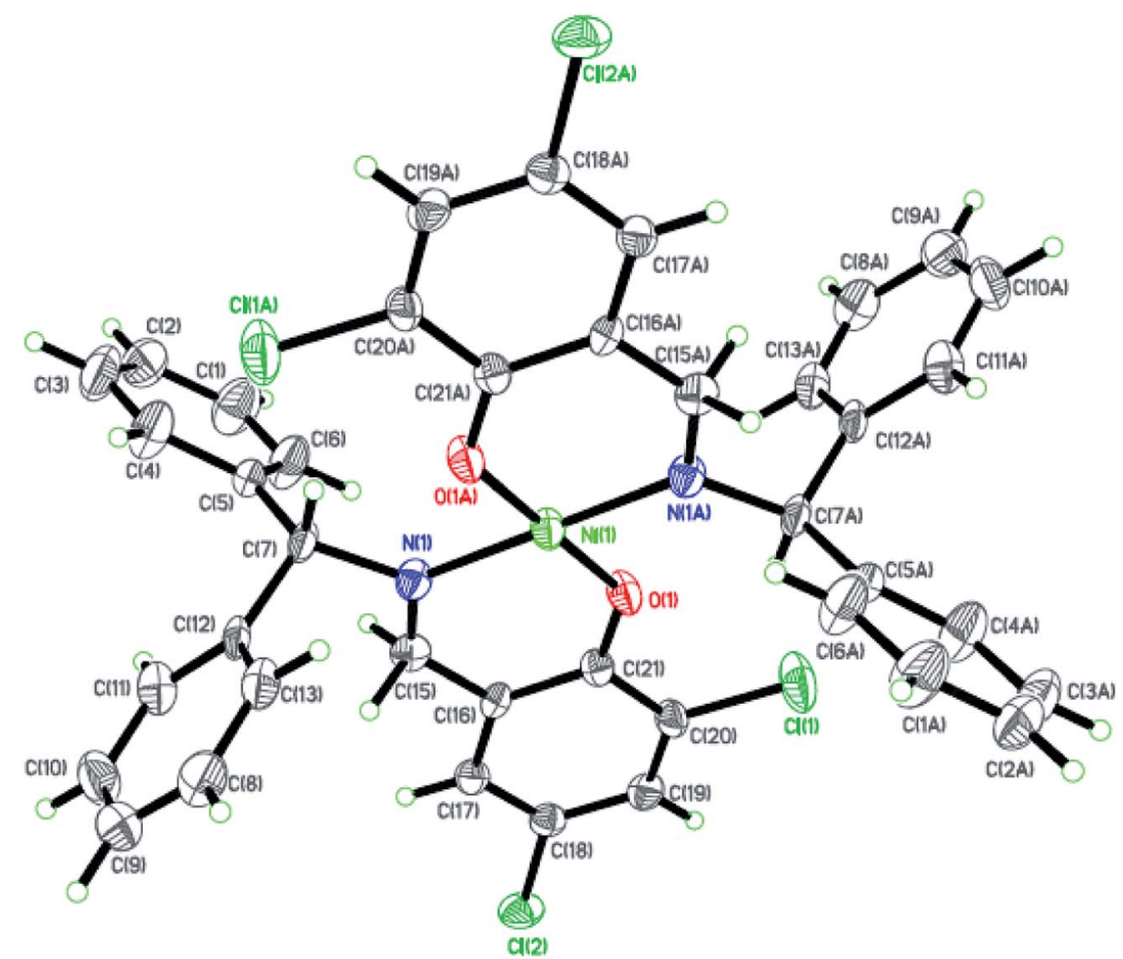

Fig. 8 ORTEP plots of Ni8 with thermal ellipsoids at the $30 \%$ probability level showing the atom-labeling scheme. Hydrogen atoms and solvent have been omitted for clarity. 
Table 3 Homopolymerization of norbornene catalyzed by Ni1-Ni8 combined with $\left.\mathrm{B}_{(} \mathrm{C}_{6} \mathrm{~F}_{5}\right)_{3}{ }^{a}$

\begin{tabular}{|c|c|c|c|c|c|c|}
\hline Ni complexes & $\mathrm{NB} / \mathrm{Ni}\left(\mathrm{mol} \mathrm{mol}^{-1}\right)$ & $\mathrm{B} / \mathrm{Ni}\left(\mathrm{mol} \mathrm{mol}^{-1}\right)$ & $T_{\mathrm{p}},{ }^{\circ} \mathrm{C}$ & Reaction time (min) & PNB Yield (\%) & Activity $^{b}$ \\
\hline Ni1 & 1000 & 10 & 60 & 5 & 60.42 & 0.68 \\
\hline Ni1 & 2000 & 10 & 60 & 5 & 70.25 & 1.62 \\
\hline Ni1 & 4000 & 10 & 60 & 5 & 27.67 & 1.25 \\
\hline Ni1 & 2000 & 5 & 60 & 5 & 29.63 & 0.67 \\
\hline Ni1 & 2000 & 20 & 60 & 5 & 58.35 & 1.32 \\
\hline Ni1 & 2000 & 10 & 80 & 5 & 66.37 & 1.50 \\
\hline $\mathrm{Ni} 2$ & 2000 & 5 & 60 & 5 & 34.67 & 0.78 \\
\hline $\mathrm{Ni} 2$ & 2000 & 10 & 60 & 5 & 73.35 & 1.65 \\
\hline $\mathrm{Ni} 2$ & 2000 & 20 & 60 & 5 & 61.85 & 1.39 \\
\hline $\mathrm{Ni3}$ & 2000 & 5 & 60 & 5 & 32.34 & 0.73 \\
\hline $\mathrm{Ni3}$ & 2000 & 10 & 60 & 5 & 71.25 & 1.61 \\
\hline Ni5 & 2000 & 5 & 60 & 5 & 33.42 & 0.75 \\
\hline $\mathrm{Ni5}$ & 2000 & 10 & 60 & 5 & 72.21 & 1.63 \\
\hline Ni5 & 2000 & 20 & 60 & 5 & 61.25 & 1.38 \\
\hline Ni6 & 2000 & 5 & 60 & 5 & 30.48 & 0.68 \\
\hline Ni6 & 2000 & 10 & 60 & 5 & 69.86 & 1.58 \\
\hline Ni6 & 2000 & 20 & 60 & 5 & 58.67 & 1.32 \\
\hline $\mathrm{Ni} 7$ & 2000 & 5 & 60 & 5 & 38.42 & 0.87 \\
\hline $\mathrm{Ni7}$ & 2000 & 10 & 60 & 5 & 85.67 & 1.93 \\
\hline Ni7 & 2000 & 20 & 60 & 5 & 70.26 & 1.59 \\
\hline Ni8 & 2000 & 5 & 60 & 5 & 40.45 & 0.91 \\
\hline Ni8 & 2000 & 10 & 60 & 5 & 91.78 & 2.07 \\
\hline Ni8 & 2000 & 20 & 60 & 5 & 73.65 & 1.66 \\
\hline
\end{tabular}

trichloromethane/methanol reverse precipitation. Finally, the polymers were dried in a vacuum at $50{ }^{\circ} \mathrm{C}$ until constant weight. The procedure was shown in Scheme 2.

\section{Results and discussion}

\subsection{Crystal structure}

Dark-green single crystals of complexes suitable for single crystal X-ray diffraction were gained by slow diffusion toluene into dichloromethane solutions. The crystallographic data were summarized in Tables 1 and 2 and Table S1 and S2. $\dagger$ The ORTEP plots of Ni1-Ni8 were shown in Fig. 1-8, respectively. CIF data of Ni1- Ni8 are available as ESI. $\dagger$ In the solid state, all the complexes are both mononuclear and four coordinate and adopt geometries best described as square planar about each nickel center, having slight distortions from idealized geometry and are quiet similar to some known nickel(II) complexes. ${ }^{19}$ In fact, the Ni-O bond lengths of Ni1 (1.816(4) $\mathrm{A})$, Ni2 (1.8295(12)

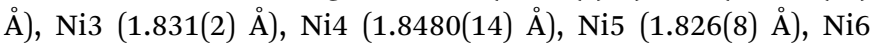

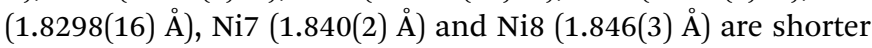
than the Ni-N bond lengths of Ni1 (1.927(4) $\AA$ ), Ni2 (1.9300(13)

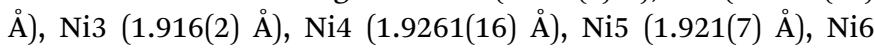
$(1.919(2) \AA)$, Ni7 (1.899(3) ̊) and Ni8 (1.931(3) A). The proligands are very stable structure and the catalysts structure are also stable and symmetrical, therefore there are very advantageous for stabilizing the activity of the catalyst. In addition, the ligand electronic effect generate different charge distribution on the nickel metal atom, and the catalytic activity markedly increased with an increase in the electrophilicity of the nickel metal center.

\subsection{Polymerization of norbornene}

A series of nickel complexes were tested with $\mathrm{B}\left(\mathrm{C}_{6} \mathrm{~F}_{5}\right)_{3}$ (ref. 43 and 44$)$ as cocatalyst in toluene and the detailed data were summarized in Table 3. In order to determine the most suitable norbornene homopolymerization conditions, the catalytic performance of $\mathrm{Ni1}$ was investigated by changing the $\mathrm{NB} / \mathrm{Ni}$ molar ratios, the $\mathrm{B} / \mathrm{Ni}$ molar ratios, and the polymerization temperature. From Table 3 we found that the polymer yields and catalytic activities depended on the reaction conditions, and the NB/Ni molar ratio at 2000/1, B/Ni molar ratio at 10/1 and the polymerization at $60{ }^{\circ} \mathrm{C}$ were the best polymerization conditions. All catalysts exhibited very high activity (up to $10^{6}$ $g_{\text {polymer }} \operatorname{mol}_{\mathrm{Ni}}^{-1} \mathrm{~h}^{-1}$ ), but there are also certain differences between the different catalysts. It can be seen that when the R2 substituent at the 5-position of the salicylaldimino aromatic ring is a strong electron-withdrawing group $(-\mathrm{Br})$, the catalytic activity is higher than that at the corresponding position for the electron-donating group $\left(-\mathrm{CH}_{3}\right.$ or $\left.-\mathrm{OCH}_{3}\right)(\mathrm{Ni} 4>\mathrm{Ni} 1, \mathrm{Ni} 2, \mathrm{Ni} 3)$, indicating that the electron-withdrawing group on the 
Table 4 Copolymerization of norbornene and 1-hexene catalyzed by Ni1-Ni2 combined with $\left.\mathrm{B}_{\left(\mathrm{C}_{6}\right.} \mathrm{F}_{5}\right)_{3}{ }^{a}$

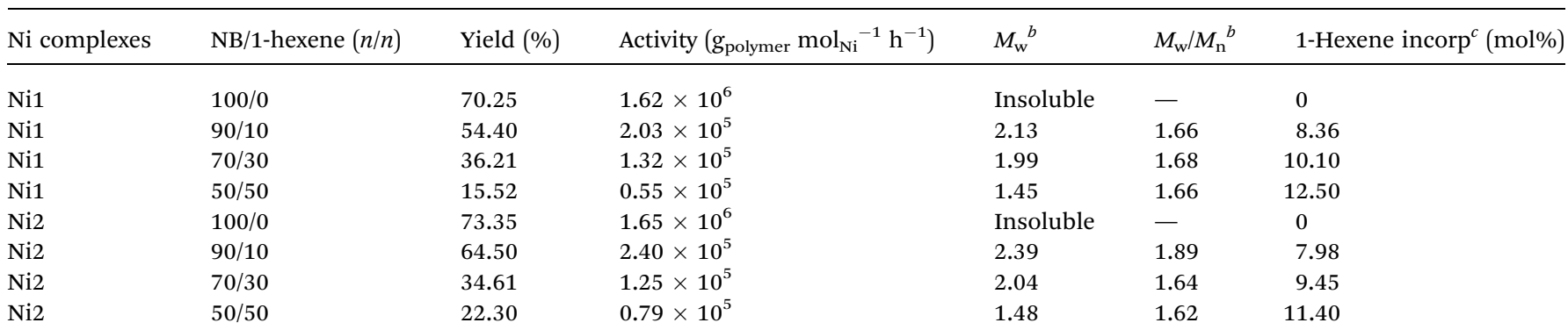

${ }^{a}$ Reaction conditions: $n[\mathrm{Ni}]=5.0 \times 10^{-6} \mathrm{~mol} ; n[\mathrm{NB}]+n[1$-hexene $]=0.01 \mathrm{~mol}$; solvent: toluene; reaction time: $30 \mathrm{~min} ;$ temperature: $60^{\circ} \mathrm{C} ; n[\mathrm{~B}] / n[\mathrm{Ni}]$ $=10 / 1 .{ }^{b}$ Determined by GPC vs. polystyrene standards in $\mathrm{CHCl}_{3}$. In unites of $10^{5} \mathrm{~g} \mathrm{~mol}^{-1}$. ${ }^{c}$ Determined by ${ }^{1} \mathrm{HNMR}$ spectroscopy in CDCl ${ }_{3}$.

salicylaldimino aromatic ring enhances the activity of the catalyst. If the salicylaldimino aromatic ring contains the same electron-donating group $\left(-\mathrm{CH}_{3}\right.$ or $\left.-\mathrm{OCH}_{3}\right)$, the 5-position substituent (R2) has a higher activity than the 3-position substituent (R1) (Ni2 > Ni5, Ni3 > Ni6), which most important reason may be that the 3-position substituent (R1) of the salicylaldimino aromatic ring increased the steric hindrance effect of the catalyst, and this had little effect on the chain transfer reaction of polynorbornene. If the 3-position (R1) and 5-position (R2) both contain strong electron-withdrawing groups $(-\mathrm{Br}$ or $-\mathrm{Cl}$ ), the catalytic activity is higher than those of the 3-position (R1) or the 5-position (R2) (Ni7 > Ni4), which indicated that the activity of the catalyst may be the result of the synergistic effect of the electronic and steric effects of the substituent. ${ }^{39,45}$ These results indicate that the strong electron-withdrawing group facilitates the increase of the activity of the catalyst, and the reactivity and the yield of the polymer increase with the electron-withdrawing ability of the salicylaldimino aromatic ring substituent.

\subsection{Copolymerization of norbornene and 1-hexene}

To further investigate the effect of the catalytic activity, Ni1 and Ni2 were applied to the copolymerization of norbornene (NB) and 1-hexene. The detailed data were summarized in Table 4 and were collected under similar conditions. It is apparent that the activities of Ni1 and Ni2 are significantly lower than those observed with norbornene homopolymerization. This may be related to the stronger binding of 1 -hexene to the $\mathrm{Ni}$ center and the longer chain structure of 1-hexene relative to norbornene, delaying the rate of chain growth compared to norbornene homopolymerization. The incorporation levels of 1-hexene are also different, Ni1 displayed higher incorporation ability for 1hexene and provided copolymers having higher 1-hexene contents (8.6-12.50 mol\%) than Ni2 (7.9-11.40 mol\%) under the same conditions. In addition, we learned that the substituents on salicylaldimino aromatic ring have a profound effect on the copolymerization reactivity of the catalyst system. ${ }^{46}$ It is well known that the methyl $\left(-\mathrm{CH}_{3}\right)$ belongs to the electron donating group and can cause an increase in the electron cloud density on the salicylaldimino aromatic ring, but the results in Table 4 showed that the $\mathrm{Ni} / \mathrm{B}\left(\mathrm{C}_{6} \mathrm{~F}_{5}\right)_{3}$ had higher activities $\left(0.79-2.40 \times 10^{5} \mathrm{~g}_{\text {polymer }} \mathrm{mol}^{-1} \mathrm{~h}^{-1}\right)$ than Ni1 $\left(0.55-2.03 \times 10^{5}\right.$ $\mathrm{g}_{\text {polymer }} \operatorname{mol}_{\mathrm{Ni}}{ }^{-1} \mathrm{~h}^{-1}$ ) did. The main reason may be that the 5position substituent $\left(-\mathrm{CH}_{3}\right)$ of the salicylaldimino aromatic ring has a certain steric hindrance effect to shield the active central axis surface, on the one hand, it can reduce chain transfer and prevent chain termination, on the other hand, it can also inhibit the occurrence of ligand rearrangement and disproportionation reaction. ${ }^{47,50}$ Besides, with the 1-hexene flexible chain increases, the polymerization activity and the polymer yield decrease. The obtained polymers had good solubility and were soluble in common organic solvents (such as $\mathrm{CHCl}_{3}, \mathrm{CH}_{2} \mathrm{Cl}_{2}$, cyclohexane, THF) as well as chlorobenzene at ambient temperature, which exhibited better solubility than PNB did.

\subsection{GPC curves of copolymers}

Gel permeation chromatography (GPC) curves of the poly(NBco-1-hexene)s with different 1-hexene flexible chain incorporation ratios achieved by the Ni1 and $\mathrm{Ni} 2 / \mathrm{B}_{(}\left(\mathrm{C}_{6} \mathrm{~F}_{5}\right)_{3}$ systems are shown in Fig. 9. GPC measurements indicated that all the polymers had high molecular weight $\left(M_{\mathrm{w}}\right)$ ranging from $1.45 \times$

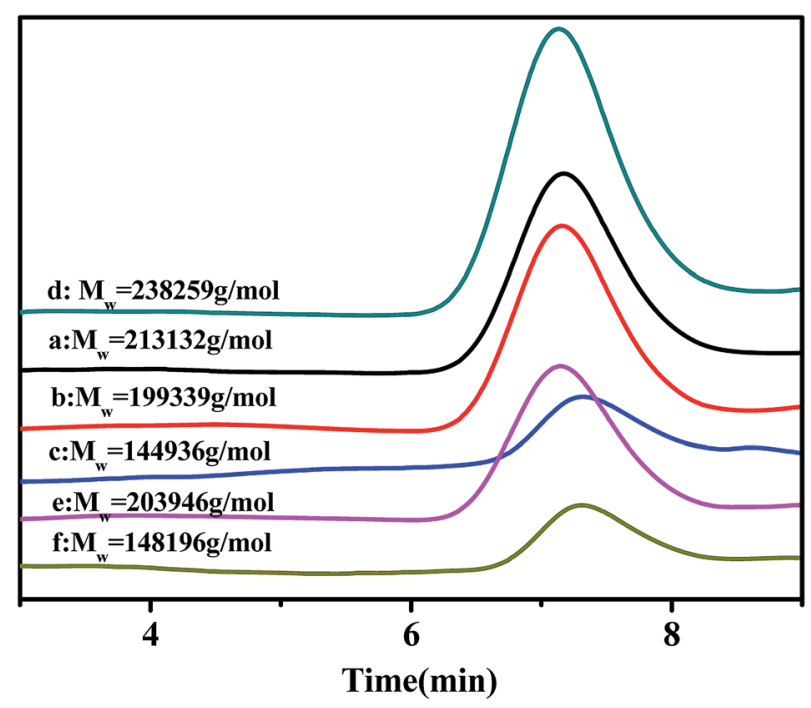

Fig. 9 The GPC curves of poly(NB-co-1-hexene)s with (a) 8.36, (b) 10.10, (c) 12.50, (d) 7.98, (e) 9.45 (f) 11.40 mol\% 1-hexene. (a), (b) and (c) obtained byNi1/B $\left(\mathrm{C}_{6} \mathrm{~F}_{5}\right)_{3}$ system, (d), (e) and (f) obtained by $\mathrm{Ni2} /$ $\mathrm{B}\left(\mathrm{C}_{6} \mathrm{~F}_{5}\right)_{3}$ system respectively. 
$10^{5}$ to $2.39 \times 10^{5} \mathrm{~g} \mathrm{~mol}^{-1}$ and decreased with the increase of 1hexene insertion rate. The distribution of molecular weight (PDI, $M_{\mathrm{w}} / M_{\mathrm{n}}$ ) is very narrow in the range of $1.62-1.89$. In addition, the GPC curves for all polymers are all unimodal, indicating that the polymerization was initiated by a single active site, which established that the resulting polymer is copolymers rather than blends of homopolymers.

\section{$3.5{ }^{1} \mathrm{H}$ and ${ }^{13} \mathrm{C}$ NMR spectra of copolymers}

The poly(NB-co-1-hexene)s were characterized by ${ }^{1} \mathrm{H}$ NMR spectroscopy and the results were shown in Fig. 10, which demonstrated that the polymers were vinyl-addition type by the absence of the resonance of the proton hydrogen connected to the double bond at 5.3-6.0 ppm. ${ }^{48}$ From the ${ }^{1} \mathrm{HNMR}$ spectra of Fig. 10, the characteristic peaks at $0.8-0.9 \mathrm{ppm}$ could be assigned to the hydrogen corresponding to $\mathrm{H}^{\prime}$, the characteristic peaks at 0.9-1.6 ppm could be attributed to the hydrogen corresponding to $\mathrm{H} 5 / \mathrm{H} 6 / \mathrm{H} 7 / \mathrm{H}^{\prime} / \mathrm{H}^{\prime} / \mathrm{H}^{\prime} / \mathrm{H}^{\prime}$, the characteristic peaks at 1.6-2.0 ppm could be attributed to the hydrogen corresponding to $\mathrm{H} 1 / \mathrm{H} 4$ and those at $2.0-2.3 \mathrm{ppm}$ could be attributed to the hydrogen corresponding to $\mathrm{H} 2 / \mathrm{H} 3 / \mathrm{H}_{2}^{\prime}$. The molar fractions of 1 -hexene could be calculated ${ }^{23}$ by ${ }^{1} \mathrm{H}$ NMR analyses and were 24.9, 22.4 and $11.3 \mathrm{~mol} \%$.

The ${ }^{13} \mathrm{C}$ NMR spectra of the poly(NB-co-1-hexene)s were shown in Fig. 11. The absorption peaks at $14.0 \mathrm{ppm}$ and 22.9 ppm were attributed to the methyl $\mathrm{C}^{\prime}$ and methylene $\mathrm{C}^{\prime}$ on the alkyl carbon chain. The absorption peaks between $45.8-$ 48.1 ppm and 50.3-54.3 ppm were attributed to methine $\mathrm{C} 1 / \mathrm{C} 4$ and $\mathrm{C} 2 / \mathrm{C} 3$ on norbornene, respectively. And the absorption peak of the copolymer between $28.8-42.8 \mathrm{ppm}$ could be attributed to $\mathrm{C} 5 / \mathrm{C} 6 / \mathrm{C} 7 / \mathrm{C}^{\prime} / \mathrm{C}^{\prime} / \mathrm{C}^{\prime} / \mathrm{C}^{\prime}$. In addition, the characteristic peak of ring-opening metathesis polymerization of norbornene was not found at $120 \mathrm{ppm}$, which further indicated that the copolymerization of norbornene and 1-hexene catalyzed by the

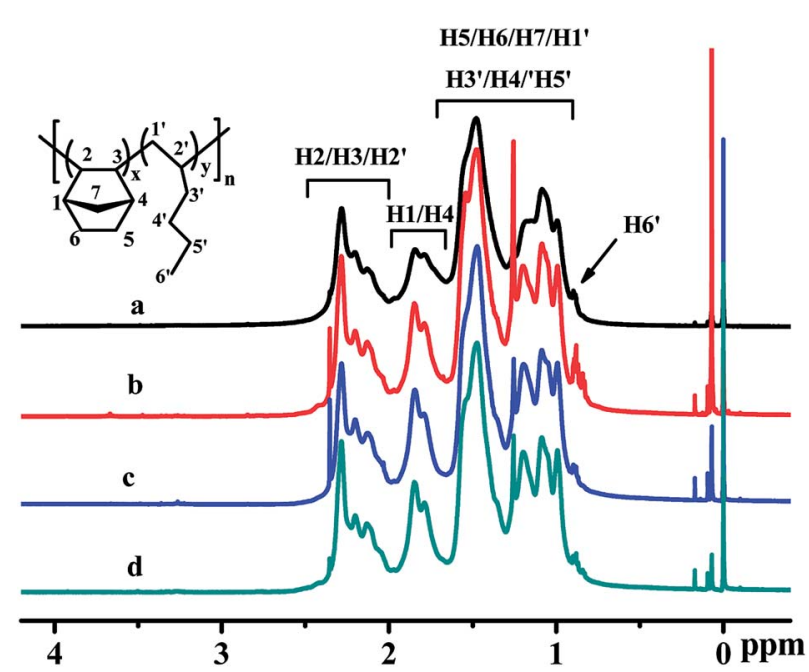

Fig. $10{ }^{1} \mathrm{H}$ NMR spectra of poly(NB-co-1-hexene)s with (a) 10.10, (b) 12.50, (c) 9.45 , (d) 11.40 mol\% 1-hexene. (a) and (b) obtained by Ni1/ $\mathrm{B}\left(\mathrm{C}_{6} \mathrm{~F}_{5}\right)_{3}$ system, (c) and (d) obtained by $\mathrm{Ni} 2 / \mathrm{B}\left(\mathrm{C}_{6} \mathrm{~F}_{5}\right)_{3}$ system respectively.

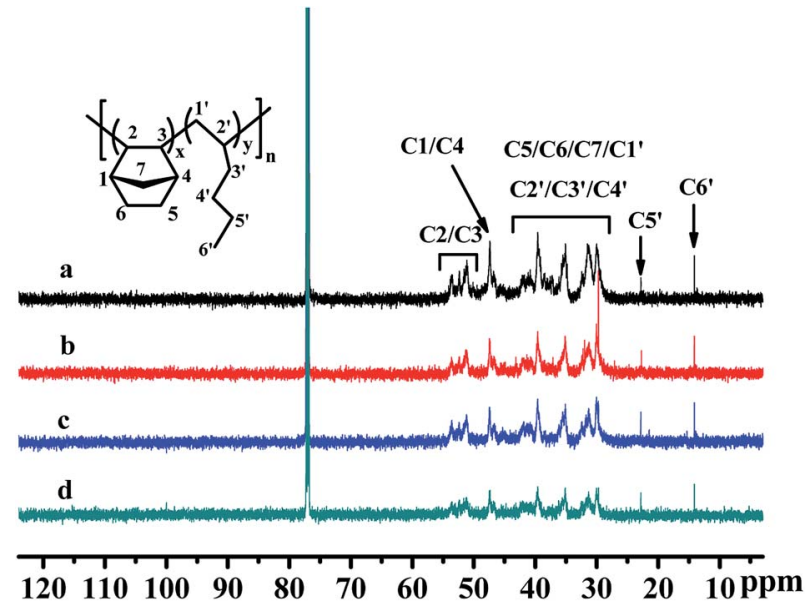

Fig. $11{ }^{13} \mathrm{C}$ NMR spectra of poly(NB-co-1-hexene)s with (a) 10.10, (b) 12.50 , (c) 9.45 , (d) 11.40 mol\% 1-hexene. (a) and (b) obtained by Ni1/ $\mathrm{B}\left(\mathrm{C}_{6} \mathrm{~F}_{5}\right)_{3}$ system, (c) and (d) obtained by $\mathrm{Ni} 2 / \mathrm{B}\left(\mathrm{C}_{6} \mathrm{~F}_{5}\right)_{3}$ system respectively.

$\mathrm{Ni1}$ and $\mathrm{Ni} 2 / \mathrm{B}\left(\mathrm{C}_{6} \mathrm{~F}_{5}\right)_{3}$ system was performed via vinyl addition mechanism.

\subsection{FTIR spectra of copolymers}

The structures of obtained copolymers were characterized by FTIR spectroscopy and shown in Fig. 12. All of the copolymers obtained from the FTIR spectrum show an absorption peak at $941 \mathrm{~cm}^{-1}$ could be assigned to the ring of bicyclo[2.2.1] heptane, as Kennedy and Makowski reported. ${ }^{49}$ There were no characteristic absorption peak at about $1620-1680 \mathrm{~cm}^{-1}$ and $960 \mathrm{~cm}^{-1}$ of the carbon-carbon double bond $(\mathrm{C}=\mathrm{C})$ of the structure of ROMP type PNB. In addition, there were also no absorptions peak at about $3050 \mathrm{~cm}^{-1}$ and $2100 \mathrm{~cm}^{-1}$ to the 1-hexene

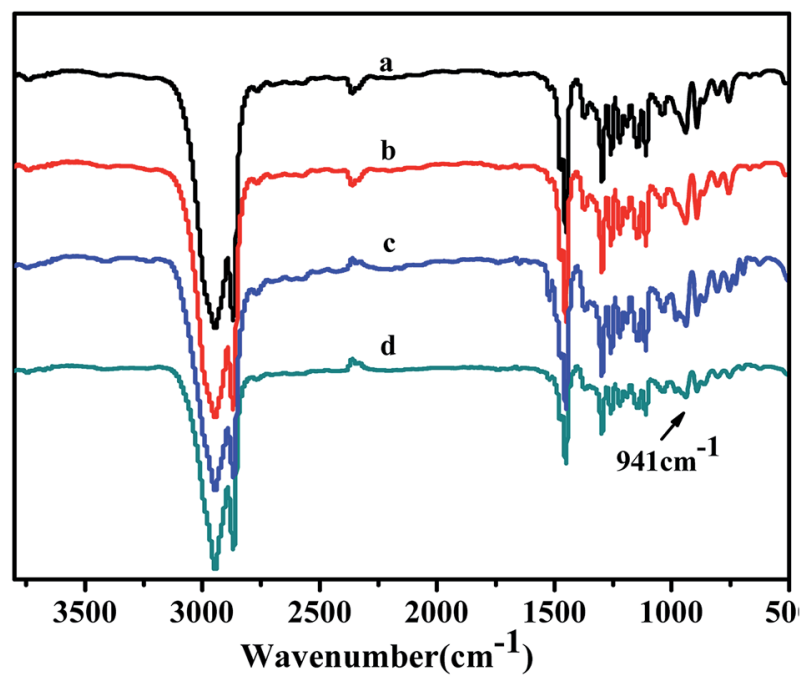

Fig. 12 FT-IR spectra of poly(NB-co-1-hexene)s with (a) 10.10, (b) 12.50 , (c) 9.45 , (d) 11.40 mol\% 1-hexene. (a) and (b) obtained by Ni1/ $\mathrm{B}\left(\mathrm{C}_{6} \mathrm{~F}_{5}\right)_{3}$ system, (c) and (d) obtained by $\mathrm{Ni} 2 / \mathrm{B}\left(\mathrm{C}_{6} \mathrm{~F}_{5}\right)_{3}$ system, respectively. 


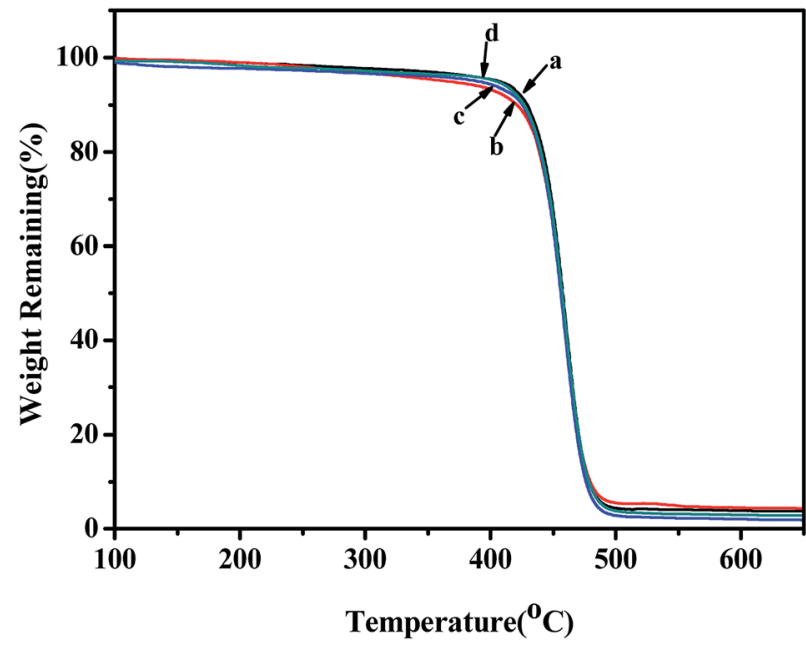

Fig. 13 TGA curves of poly(NB-co-1-hexene)s with (a) 10.10, (b) 12.50, (c) 9.45 , (d) 11.40 mol\% 1-hexene. (a) and (b) obtained by Ni1/B $\left(\mathrm{C}_{6} \mathrm{~F}_{5}\right)_{3}$ system, (c) and (d) obtained by $\mathrm{Ni} 2 / \mathrm{B}\left(\mathrm{C}_{6} \mathrm{~F}_{5}\right)_{3}$ system, respectively.

characteristic trans form of $\mathrm{C}=\mathrm{C}$ and $\mathrm{C}-\mathrm{H}$ bonds stretching. All these results shown that norbornene and 1-hexene were successfully copolymerized and further indicated 1-hexene had been inserted into the copolymers chains rather than simple blends.

\subsection{TGA analyses of copolymers}

The TGA curves of poly(NB-co-1-hexene) with different 1-hexene insertion rates gained with the $\mathrm{Ni} 1$ and $\mathrm{Ni} 2 / \mathrm{B}\left(\mathrm{C}_{6} \mathrm{~F}_{5}\right)_{3}$ catalytic system were shown in Fig. 13. The thermal properties of all the copolymers obtained from the TGA curve were similar and all began to decompose within the range of $350-450{ }^{\circ} \mathrm{C}$. In addition, as the insertion of the 1-hexene content in the polymer

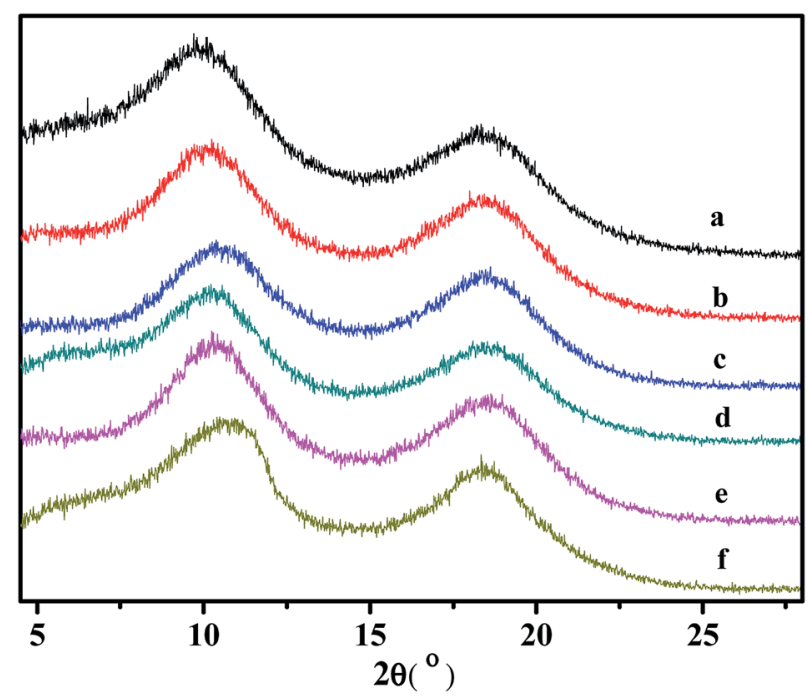

Fig. 14 WXRD spectra of poly(NB-co-1-hexene)s with (a) $8.36 \%$, (b) 10.10, (c) 12.50, (d) 7.98, (e) 9.45, (f) 11.40 mol\% 1-hexene. (a), (b) and (c) obtained by $\mathrm{Ni1} / \mathrm{B}\left(\mathrm{C}_{6} \mathrm{~F}_{5}\right)_{3}$ system, (d), (e) and (f) obtained by $\mathrm{Ni2} /$ $\mathrm{B}\left(\mathrm{C}_{6} \mathrm{~F}_{5}\right)_{3}$ system, respectively. chain increased, the thermal decomposition temperature decreased, but it still had good thermal stability.

\subsection{WXRD analyses of the copolymers}

Some supporting information about the conformation of the poly(NB-co-1-hexene)s were gained with wide-angle X-ray diffraction (WAXD), as shown in Fig. 14. No Bragg diffraction appears in the spectral region of the crystal, so the polymers were noncrystalline. Two broad halos at 2 values of $10.42-10.58^{\circ}$ and $18.04-18.28^{\circ}$ were characteristic peaks for polynorbornene. When the catalytic system is changed, the insertion rate of 1hexene is different, but the change of the diffraction peak is less obvious and the chain spacing of all the polymers is not much different. These all results shown that the packing density of the copolymers changed little when the catalytic system changed. The interchain distances were computed according to eqn (1) and amounted to be 8.50 and $4.77 \AA$ A, separately.

$$
d_{\text {inerchain }}=1.22 d_{\text {Bragg }}=1.22 \frac{\lambda}{2 \sin \theta}
$$

\subsection{The transparency properties of the copolymer films}

The UV-Vis curves of poly(NB-co-1-hexene)s films with different 1-hexene insertion rate were shown in Fig. 15. The spectrum shown that the transmittance of the copolymer film in the visible light range of 400-800 $\mathrm{nm}$ were all over $80 \%$. Although the transmittance of the copolymers were lower than the polynorbornene (92\%), the copolymer still had good light transmittance. In addition, as the insertion rate of 1-hexene in the copolymer was increased, the light transmittance of the polymer films were decreased, which indicated that the addition of 1-hexene had a negative effect on the light transparency of the copolymer films.

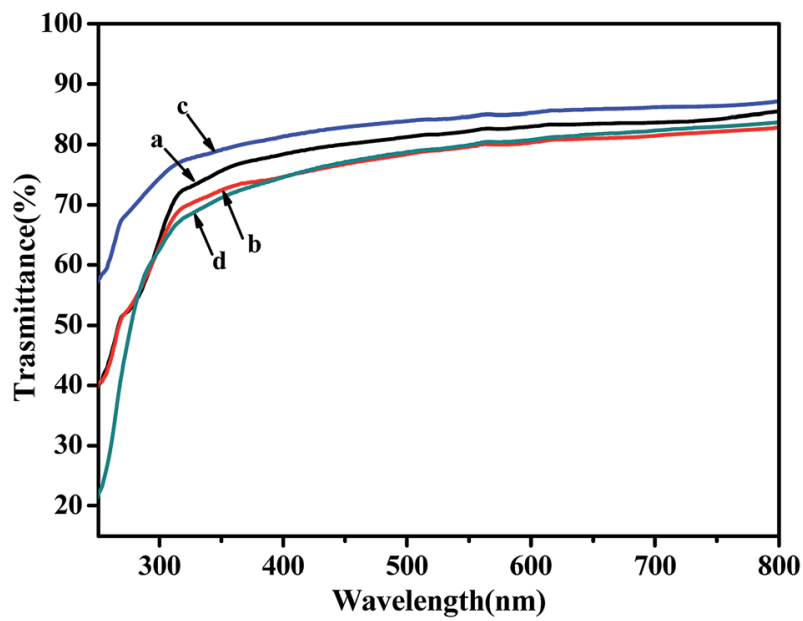

Fig. 15 The UV-Vis curves of poly(NB-Co-1-hexene)s membranes with (a) 10.10, (b) 12.50, (c) 9.45, (d) 11.40 mol\% 1-hexene. (a) and (b) obtained by Ni1/B $\left(\mathrm{C}_{6} \mathrm{~F}_{5}\right)_{3}$ system, (c) and (d) obtained by Ni2/B(C$\left.{ }_{6} \mathrm{~F}_{5}\right)_{3}$ system, respectively. 


\section{Conclusions}

Eight bis-(salicylaldehyde-benzhydrylimino)nickel complexes with different electron groups (Ni1-Ni8) were synthesized and characterized by single crystal X-ray diffraction, and these catalysts achieved homopolymerization of norbornene with $\mathrm{B}\left(\mathrm{C}_{6} \mathrm{~F}_{5}\right)_{3}$ as cocatalyst, and the activity reached $10^{6} \mathrm{~g}_{\mathrm{PNB}} \mathrm{mol}_{\mathrm{Ni}}{ }^{-1}$ $\mathrm{h}^{-1}$. The Ni1 and Ni2 two catalysts also displayed high activities (up to $10^{5} \mathrm{~g}_{\text {polymer }} \mathrm{mol}_{\mathrm{Ni}}{ }^{-1} \mathrm{~h}^{-1}$ ) towards the copolymerization of norbornene and 1-hexene, and Ni2 exhibited higher activity than Ni1 did, and the catalytic activity decreased with the increased of the insertion rate of 1-hexene. The poly(NB-co-1hexene)s showed better solubility and high molecular weights (up to $10^{5} \mathrm{~g} \mathrm{~mol}^{-1}$ ) than that of the PNB and were confirmed to be noncrystalline. The analyses of the structure and properties of the copolymers showed that the polymers of norbornene and 1-hexene were copolymers rather than blends of the two. In addition, the copolymerization of norbornene with 1-hexene was carried out via a vinyl-addition copolymerization mode and the poly(NB-co-1-hexene) copolymer had good thermal stability.

\section{Conflicts of interest}

There are no conflicts to declare.

\section{Acknowledgements}

This work was supported by the National Natural Science Foundation of China (21674045 and 51463014).

\section{References}

1 A. Ravasio, C. Zampa, L. Boggioni, I. Tritto, J. Hitzbleck and J. Okuda, Macromolecules, 2008, 41, 9565-9569.

2 Y. L. Li, J. X. Yang, B. Wang and Y. S. Li, RSC Adv., 2016, 6, 59590-59599.

3 S. Losio, I. Tritto, L. Boggioni, G. Mancini, G. Luciano, L. Tofani, C. Viglianisi, S. Menichetti, M. C. Sacchi and P. Stagnaro, Polym. Degrad. Stab., 2017, 144, 167-175.

4 R. T. Mathers, K. Damodaran, M. G. Rendos and M. S. Lavrich, Macromolecules, 2009, 42, 1512-1518.

5 M. Weck, P. Schwab and R. H. Grubbs, Macromolecules, 1996, 29, 1789-1793.

6 B. O. Orturk, G. Calisgan, H. Ozer and S. K. Sehitoglu, React. Funct. Polym., 2018, 126, 63-73.

7 X. Zeng, J. J. Luo, T. Zhou, T. H. Chen, X. Zhou, K. L. Wu, Y. Zou, G. H. Xie, S. L. Gong and C. L. Yang, Macromolecules, 2018, 51, 1598-1604.

8 F. Fan, C. Cai, L. Gao, J. Li, P. Zhang, G. Y. Li, C. X. Li and G. L. Yu, Polym. Chem., 2017, 8, 6709-6719.

9 G. Myagmarsuren, K. S. Lee, O. Y. Jeong and S. K. Ihm, Catal. Commun., 2003, 4, 615-619.

10 P. Hu, Y. L. Qiao, J. Q. Wang and G. X. Jin, Organometallics, 2012, 31, 3241-3247.

11 G. Siedle, P. G. Lassahn, V. Lozan, C. Janiak and B. Kersting, Dalton Trans., 2007, 52-61, DOI: 10.1039/b613789j.

12 X. C. Shi and G. X. Jin, Organometallics, 2012, 31, 4748-4754.
13 R. Zhuang, H. Liu, J. Guo, B. Dong, W. P. Zhao, Y. M. Hu and X. Q. Zhang, Eur. Polym. J., 2017, 93, 358-367.

14 M. Eo, D. Han, M. H. Park, M. Hong, Y. Do, S. Yoo and M. H. Lee, Eur. Polym. J., 2014, 51, 37-44.

15 S. D. Tsai and R. A. Register, Macromol. Chem. Phys., 2018, 219, 1800059-1800065.

16 A. A. Antonov, N. V. Semikolenova, V. A. Zakharov, W. J. Zhang, Y. H. Wang, W. H. Sun, E. P. Talsi and K. P. Bryliakov, Organometallics, 2012, 31, 1143-1149.

17 K. T. Wang, J. B. Wang, Y. G. Li, L. Pan and Y. S. Li, Polymers, 2017, 9, 353-363.

18 L. Chen, Z. C. Zhong, C. Chen, X. H. He and Y. W. Chen, J. Organomet. Chem., 2014, 752, 100-108.

19 X. H. He, Y. P. Yang, S. L. Wang, Z. L. Han, G. S. Tu, F. Zhang, S. M. Huang, Z. J. Wang and D. F. Chen, RSC Adv., 2017, 7, 48745-48753.

20 E. Ihara, S. Honjyo, K. Kobayashi, S. Ishii, T. Itoh, K. Inoue, H. Momose and M. Nodono, Polymer, 2010, 51, 397-402.

21 J. Kiesewetter, B. Arikan and W. Kaminsky, Polymer, 2006, 47, 3302-3314.

22 P. Huo, W. Y. Liu, X. H. He and G. Q. Mei, J. Polym. Res., 2015, 22, 194-210.

23 X. H. He, Y. J. Deng, Z. L. Han, Y. P. Yang and D. F. Chen, J. Polym. Sci., Polym. Chem. Ed., 2016, 54, 3495-3505.

24 W. Ochedzan-Siodlak and A. Bihun, Polym. Bull., 2017, 74, 2799-2817.

25 R. Tanaka, R. Matsuzaki, Y. Nakayama and T. Shiono, J. Polym. Sci., Polym. Chem. Ed., 2017, 55, 2136-2140.

26 L. P. He, J. Y. Liu, Y. G. Li, S. R. Liu and Y. S. Li, Macromolecules, 2009, 42, 8566-8570.

27 E. S. M. Blaakmeer, G. Antinucci, A. Correa, V. Busico, E. R. H. van Eck and A. P. M. Kentgens, J. Phys. Chem. C, 2018, 122, 5525-5536.

28 R. M. Golding, R. O. Pascual, C. Suvanprakorn and I. G. Dance, Bull. Korean Chem. Soc., 2006, 27, 1752-1756.

29 N. Diteepeng, X. Y. Tang, X. H. Hou, Y. S. Li, K. Phomphrai and K. Nomura, Dalton Trans., 2015, 44, 12273-12281.

30 A. El-Batta, A. W. Waltman and R. H. Grubbs, J. Organomet. Chem., 2011, 696, 2477-2481.

31 M. P. Weberski, C. L. Chen, M. Delferro and T. J. Marks, Chem.-Eur. J., 2012, 18, 10715-10732.

32 D. P. Song, X. C. Shi, Y. X. Wang, J. X. Yang and Y. S. Li, Organometallics, 2012, 31, 966-975.

33 L. Piche, J.-C. Daigle, R. Poli and J. P. Claverie, Eur. J. Inorg. Chem., 2010, 4595-4601.

34 W. H. Yang, Z. F. Ma, J. Yi and W. H. Sun, Catalysts, 2017, 7, 120-134.

35 F. He, X. Hao, X. Cao, C. Redshaw and W. H. Sun, J. Organomet. Chem., 2012, 712, 46-51.

36 Z. G. Cai, R. Harada, Y. Nakayama and T. Shiono, Macromolecules, 2010, 43, 4527-4531.

37 W. Kaminsky and A. Laban, Appl. Catal., A, 2001, 222, 47-61.

38 T. Shiono, M. Sugimoto, T. Hasan, Z. Cai and T. Ikeda, Macromolecules, 2008, 41, 8292-8294.

39 D. P. Song, J. Q. Wu, W. P. Ye, H. L. Mu and Y. S. Li, Organometallics, 2010, 29, 2306-2314. 
40 Y. P. Xing, Y. W. Chen and X. H. He, J. Polym. Eng., 2012, 32, 7-12.

41 J. W. Tian, X. H. He, J. Y. Liu, X. D. Deng and D. F. Chen, RSC Adv., 2015, 5, 61851-61860.

42 P. Huo, J. B. Li, W. Y. Liu, G. Q. Mei and X. H. He, RSC Adv., 2017, 7, 51858-51863.

43 B. L. Goodall, M. I. Iii and L. F. Rhodes, Macromol. Symp., 1995, 89, 421-432.

44 Y. Jang, H. K. Sung and H. Kwag, Eur. Polym. J., 2006, 42, 1250-1258.

45 D. P. Song, W. P. Ye, Y. X. Wang, J. Y. Liu and Y. S. Li, Organometallics, 2009, 28, 5697-5704.
46 E. D. Yao, J. C. Wang, Z. T. Chen and Y. G. Ma, Macromolecules, 2014, 47, 8164-8170.

47 T. R. Younkin, E. F. Conner, J. I. Henderson, S. K. Friedrich, R. H. Grubbs and D. A. Bansleben, Science, 2000, 287, 460462.

48 M. C. Sacchi, M. Sonzogni, S. Losio, F. Forlini, P. Locatelli, I. Tritto and M. Licchelli, Macromol. Chem. Phys., 2001, 202, 2052-2058.

49 J. P. Kennedy and H. S. Makowski, J. Macromol. Sci., Part A, 1967, 1, 345-370.

50 S. D. Ittel, L. K. Johnson and M. Brookhart, Chem. Rev., 2001, 100, 1169-1204. 